\title{
1,3,4-Thiadiazole Scaffold: As Anti-Epileptic Agents
}

\section{Tulika Anthwal and Sumitra Nain* \\ Department of Pharmacy, Banasthali Vidyapith, Banasthali, India}

A wide range of biological activities is exhibited by 1,3,4-thiadiazole moiety such as antidiabetic, anticancer, anti-inflammatory, anticonvulsant, antiviral, antihypertensive, and antimicrobial. To date, drugs such as butazolamide, and acetazolamide. Several modifications have been done in the 1,3,4-thiadiazole moiety which showed good potency as anticonvulsant agents which are highly effective and have less toxicity. After in-depth literature survey in this review, we have compiled various derivatives of 1,3,4-thiadiazole scaffold as anticonvulsant agents.

Keywords: anti-convulsant, pharmacophoric pattern, 1,3,4 thiadiazole, structural activity relationship, antihypertensive

\section{INTRODUCTION}

OPEN ACCESS

Edited by:

Simone Di Micco,

European Biomedical Research

Institute of Salerno (EBRIS), Italy

Reviewed by:

DR Reshma Rani,

Amity University, India

Ashok K. Shakya

Al-Ahliyya Amman University, Jordan

*Correspondence:

Sumitra Nain

nainsumitra@gmail.com

Specialty section:

This article was submitted to Medicinal and Pharmaceutical

Chemistry,

a section of the journal

Frontiers in Chemistry

Received: 08 March 2021 Accepted: 28 October 2021

Published: 21 January 2022

Citation:

Anthwal T and Nain S (2022) 1,3,4-

Thiadiazole Scaffold: As Anti-

Epileptic Agents.

Front. Chem. 9:671212.

doi: $10.3389 /$ fchem.2021.671212
Epilepsy is a CNS disease in which the activity of neuronal cells becomes abnormal, causing seizures, loss, or disturbance of consciousness with or without convulsion (Tripathi, 2013). In epileptic patients, a temporary disturbance in the messaging systems between brain cells is caused by a sudden surge of electrical activity due to which they experience recurrent seizures (Klein, 2019). Various factors are involved in the occurrence of epilepsy such as genetic factors, head trauma, conditions of the brain, infectious diseases, and prenatal injury to the brain. Electroencephalogram (EEG), CT scan, MRI, etc., are used to diagnose epilepsy seizures (Holland, 2018).

The molecular structure of a compound is responsible for various pharmacological activities, and mostly heterocyclic moieties have diverse activities. This scaffold (Figure 1A) derivatives possess a wide range of biological activities such as anticancer/antitumor (Janowska et al., 2020; Cevik et al., 2020; Gomha et al., 2017; Flefel et al., 2017; Ningegowda et al., 2017), anticonvulsant (Khatoon et al., 2018; Bhandari et al., 2008; Jatav et al., 2008; Foromadi et al., 2007; Almasirad et al., 2007; Dawood et al., 2006; Dogan et al., 2002; Varvaresou et al., 1998; Khazi et al., 1996; Stillings et al., 1986; Chapleo et al., 1986), antidiabetic (Vaishnav et al., 2017; Datar and Deokule, 2014; Thrilochana et al., 2014), anti-inflammatory (Cristina et al., 2018; Schenone et al., 2006), antidepressant (Can et al., 2012), antihypertensive (Samel and Pai, 2010), antiviral (Serban et al., 2020; Brai et al., 2019), antimicrobial (Gowda et al., 2020; Merugu et al., 2020; Mutchu et al., 2019; Sekhar et al., 2018; Joseph et al., 2015), antioxidant (Yakan, 2021; Gowda et al., 2020), anti-leishmanial (Tahghighi and Babalouei, 2017; Sadat-Ebrahimi et al., 2019), and neuroprotective (Skrzypeka et al., 2021). The biological activities of several synthesized derivatives of 1,3,4-thiadiazole are based on assumptions like "the $=\mathrm{N}$-C-Smoiety's presence and strong aromaticity of the ring, which is responsible for providing low toxicity and great in vivo stability. The derivatives of 1,3,4-thiadiazole have enormous capability to produce

Abbreviation: $\mathrm{Br}$, Bromine; $\mathrm{Cl}$, chlorine; $\mathrm{ED}_{50}$, effective dose; $\mathrm{F}$, fluorine; HPTLC, high-performance thin-layer chromatography; IR, infrared spectroscopy; $\mathrm{LD}_{50}$, lethal dose; MES, maximal electroshock method; nm, nanometer; NMR, nuclear magnetic resonance; $\mathrm{OCH}_{3}$, methoxy; PTZ, pentylenetrazole-induced seizure method; SAR, structure-activity relationship; TLC, thin-layer chromatography. 

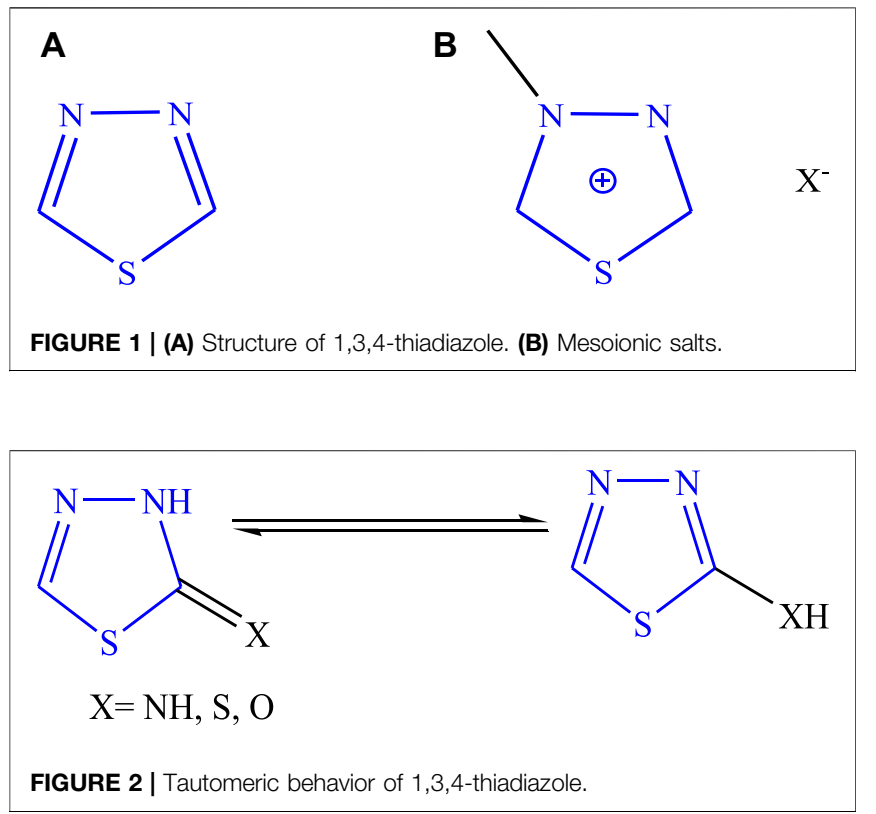

mesoionic salts (Figure 1B) and due to this behavior, they can interact strongly with biomolecules (proteins and DNA)" and can easily cross the blood-brain barrier (Haider et al., 2015; Serban et al., 2018).

This scaffold was discovered in 1882 by Emil Fischer, although the true properties of the ring were described by Freund and Kuh. It is also known as 4-azathiazole or 3,4dioxythiophene (Manimaran et al., 2017; Joseph et al., 2015). It is affected by the strong base and forms a ring cleavage when strong bases are added to it and become stable as acids are added to it. The tautomeric behavior (Figure 2) occurs due to 2-hydroxy-, mercapto-, and amino derivatives, and it is a pseudo-aromatic molecule in nature. The dipole moment of the moiety is $3.25 \mathrm{D}$; at the second and fifth positions, nucleophilic attack takes place. It is a stable colorless compound with a melting point of $42^{\circ} \mathrm{C}$, it is potent for oxidation and reduction in alkali/acids and shows no ultraviolet absorption maximum up to $220 \mathrm{~nm}$ (Raj et al., 2015). Numerous drugs are available in the market of this moiety used for diverse biological activities such as butazolamide (Figure 3A), acetazolamide (Figure 3B) (Loscher et al., 2011; Jain et al., 2013).

1,3,4-Thiadiazole moiety also has patent research on various activities such as potent agonist of the S1P1 receptor (Poveda et al., 2010), the antagonist of voltage-gated sodium channels (Stamos et al., 2009), proton pump inhibitor (Karimian et al., 1997), $\beta$-adrenergic blocking agents (Belanger, 1979).

\section{The Pharmacophoric Pattern of 1,3,4-Thiadiazole Responsible for Anticonvulsant Activity}

A pharmacophore is a 3D structure to which several ligands can bind to the same protein in the same binding site by observing their common arrangements of ligands to identify a biologically active compound.

Nowadays, the most applicable way to design a new drug molecule that has a high affinity to bind with a specific receptor to give appropriate results is none other than a pharmacophorebased approach (Raj et al., 2015).

The thiadiazole ring exhibits various biological activities, but there are various important features due to which the thiadiazole ring acts as an anticonvulsant agent such as "a hydrogen bonding domain (HBD), Hydrophobic aryl ring (Ar), another distal Hydrophobic site, an electron-donor group (D)" (Pandey, 2002).

\section{Mechanism of Action of 1,3,4-Thiadiazole in Treatment of Epilepsy}

There are several non-synaptic and synaptic mechanisms which are responsible for treatment of epilepsy. Literature survey reveals the importance of GABA receptors in the mechanism and treatment of epilepsy by releasing chloride ions and preventing the abnormal electrical impulse in the brain. The essential features of this moiety which is responsible for anticonvulsant activity include an electron-donor group, a hydrophobic aryl ring, a distal hydrophobic site, and a hydrogen bonding domain. 1,3,4Thiadiazole prevents neurons from firing in the brain by releasing the chloride ions due to the GABAA pathway (Khatoon et al., 2018; Bhattacharya et al., 2019).

\section{1,3,4-Thiadiazole Derivatives as Anti-Convulsant}

A new Schiff-base derivative of 5-amino-1,3,4-thiadiazole was synthesized using glacial acetic acid and ethanol by the condensation method by Aliyu et al. (Figure 4). The synthesized compounds were characterized by analytical

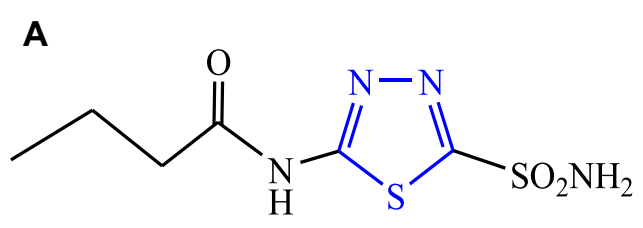<smiles>CC(=O)Nc1nnc(S(N)(=O)=O)s1</smiles>

FIGURE 3 | (A) Butezolamide. (B) Acetazolamide. 


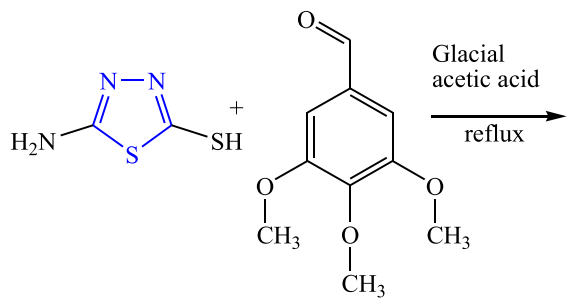<smiles>COc1cc(/C=N/c2nnc(S)s2)cc(OC)c1OC</smiles>

FIGURE 4 | Systematic scheme for synthesizing the 5-amino-1,3,4-thiadiazole derivative.

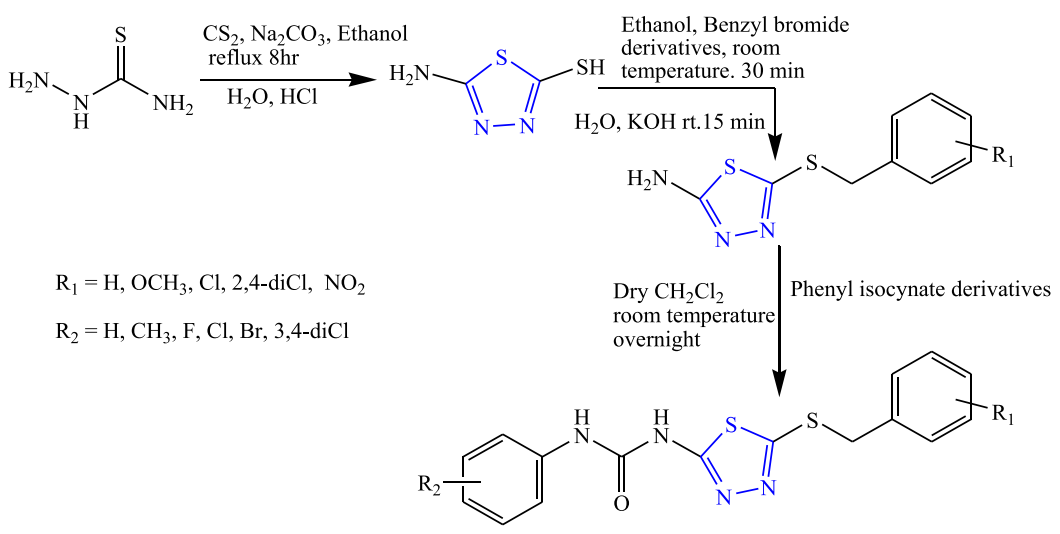

FIGURE 5 | Systematic scheme for synthesizing 2,5-disubstituted 1,3,4-thiadiazoles derivatives.

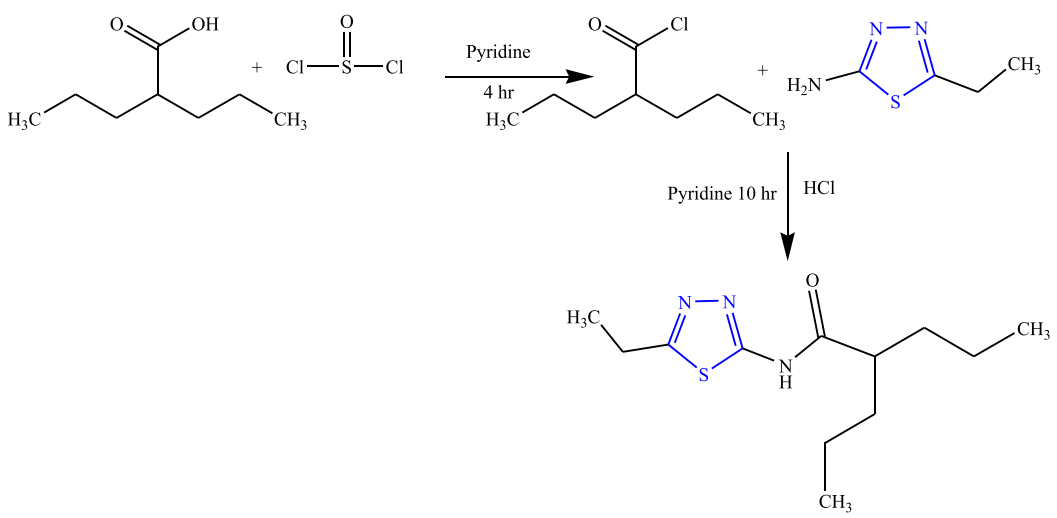

FIGURE 6 | Systematic scheme for synthesizing the valproic acid analog.

spectroscopy [FT-IR, NMR $\left({ }^{1} \mathrm{H}{ }^{13} \mathrm{C}\right), \mathrm{MS}, \mathrm{UV}$ ] and were evaluated for in-vivo anticonvulsant activity by maximal electroshock seizure (MES), phenobarbital-induced sleep test, and the rotarod method (neurotoxicity) using sodium valproate and phenytoin as the standard drug. Molecular docking studies were also performed using ChemSketch 1.21 software. The SAR activity revealed that the synthesized compound becomes more lipophilic and showed good antiepileptic activity. It concluded that the synthesized compound named 5-[(E)-(3,4,5-trimethoxybenzylidene) amino]-1,3,4-thiadiazole-2-thiol showed the H-bonding for the donor/acceptor group at a range of 4.18-6.88 $\AA$. $\mathrm{LD}_{50}$ was found to be $3,807.87 \mathrm{mg} / \mathrm{kg}$ while it displayed $66.67 \%$ protection at $100 \mathrm{mg} / \mathrm{kg}$ for the MES method and $80 \%$ protection was observed 


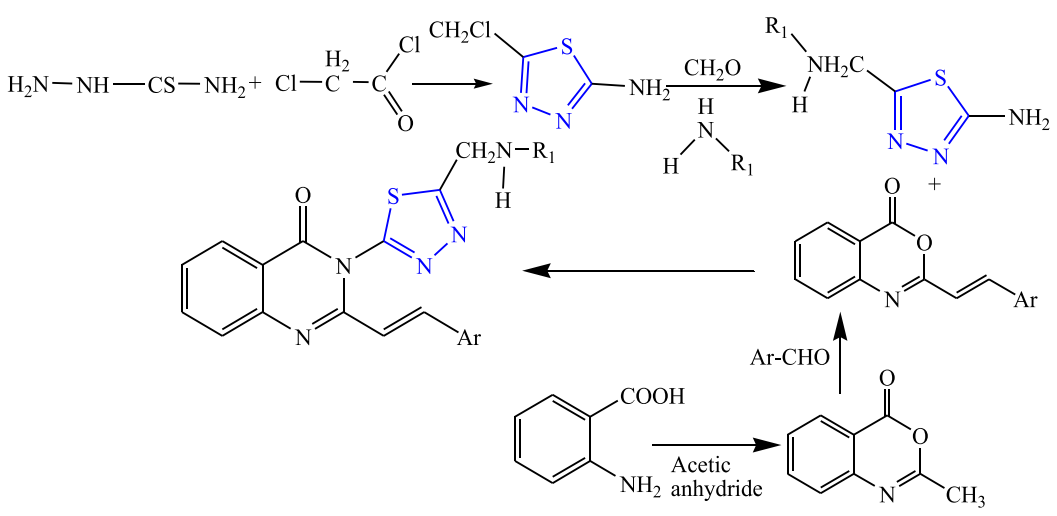

$\mathrm{R}_{1}=\mathrm{C}_{6} \mathrm{H}_{5} \mathrm{Cl}, \mathrm{C}_{6} \mathrm{H}_{5} \mathrm{Br}, \mathrm{C}_{6} \mathrm{H}_{5} \mathrm{NO}_{2}, \mathrm{C}_{6} \mathrm{H}_{5} \mathrm{~F}, \mathrm{C}_{6} \mathrm{H}_{5} \mathrm{CH}_{3}, \mathrm{C}_{6} \mathrm{H}_{5} \mathrm{OCH}_{3}, \mathrm{C}_{6} \mathrm{H}_{5} \mathrm{C}_{2} \mathrm{H}_{5}$

$\mathrm{Ar}=\mathrm{C}_{6} \mathrm{H}_{5}, \mathrm{C}_{6} \mathrm{H}_{5} \mathrm{NO}_{2}, \mathrm{C}_{6} \mathrm{H}_{5} \mathrm{CH}_{3}, \mathrm{C}_{6} \mathrm{H}_{5} \mathrm{Cl}, \mathrm{C}_{6} \mathrm{H}_{5} \mathrm{OCH}_{3}$

FIGURE 7 | Systematic scheme for synthesizing derivatives of (E)-3-(5-(substituted amino methyl)-1,3,4-thiadiazol-2-yl)-2-styrylquinazolin-4(3H)-one.

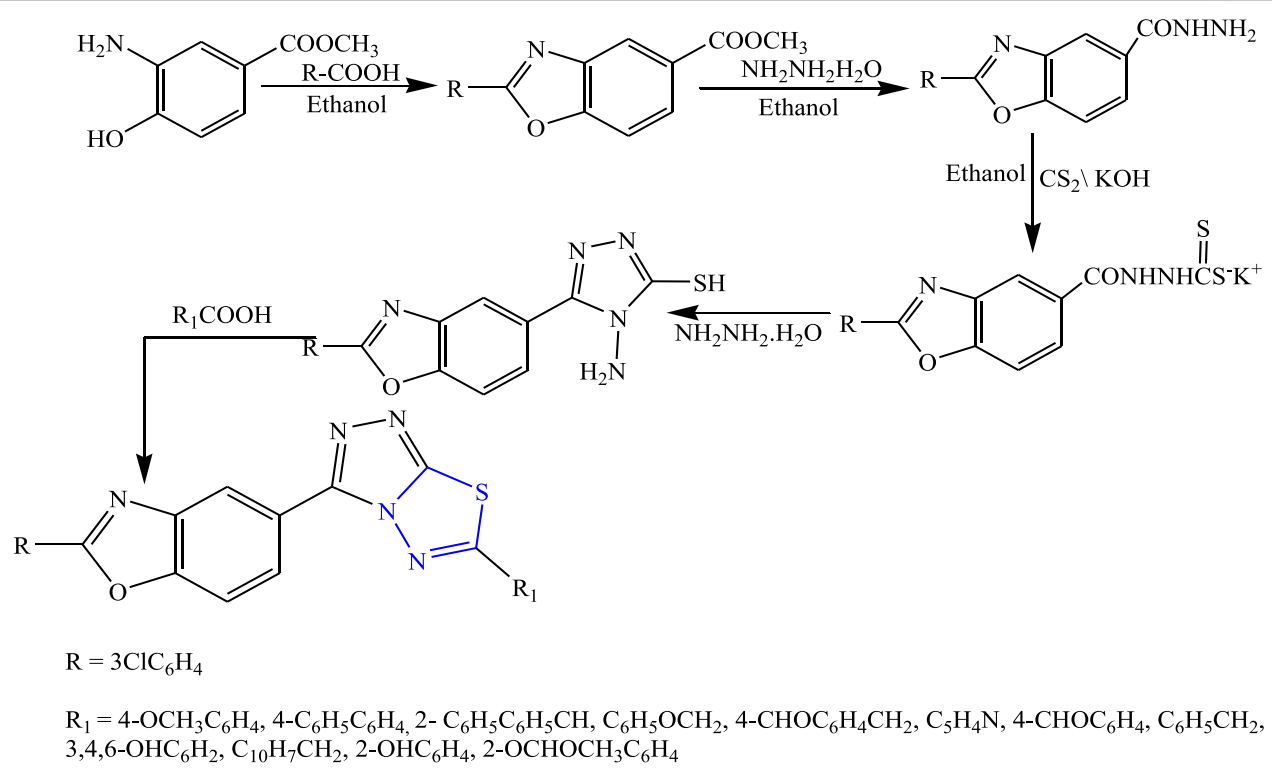

FIGURE 8 | Systematic scheme for synthesizing 1,2,4-triazole-1,3,4-thiadiazole derivatives.

at $100 \mathrm{mg} / \mathrm{kg}$ in the PTZ method. The compound was proven to be potent for both the method with no toxicity by two mechanisms GABA and the voltage-gated ion channel (Aliyu et al., 2021).

Several derivatives of 1,3,4-thiadiazole were synthesized by substituting with phenyl isocyanate derivatives at the second and fifth positions, taking thiosemicarbazide and carbon disulfide as a precursor by Toolabi et al. (Figure 5). The synthesized compounds were characterized by analytical spectroscopy (IR, NMR, MS, HPLC) and were evaluated for in-vivo anticonvulsant activity by MES, phenobarbital-induced sleep test, and rotarod method using diazepam as the standard drug. Molecular docking was also performed using a BZD-binding pocket of the GABA receptor, and 11 compounds were found to be effective using AutoDock 4.2.1 software. The SAR activity of the compound concluded that an unsubstituted compound (i.e., compound containing hydrogen) showed good anticonvulsant activity as compared to the compound containing a halo group, while moderate activity was shown by a compound containing three methoxy groups. A decrease in activity was observed when the compound was substituted by two bromo and four methyl groups at phenyl urea. It is concluded that the $\mathrm{Cl}$ substitution on the 


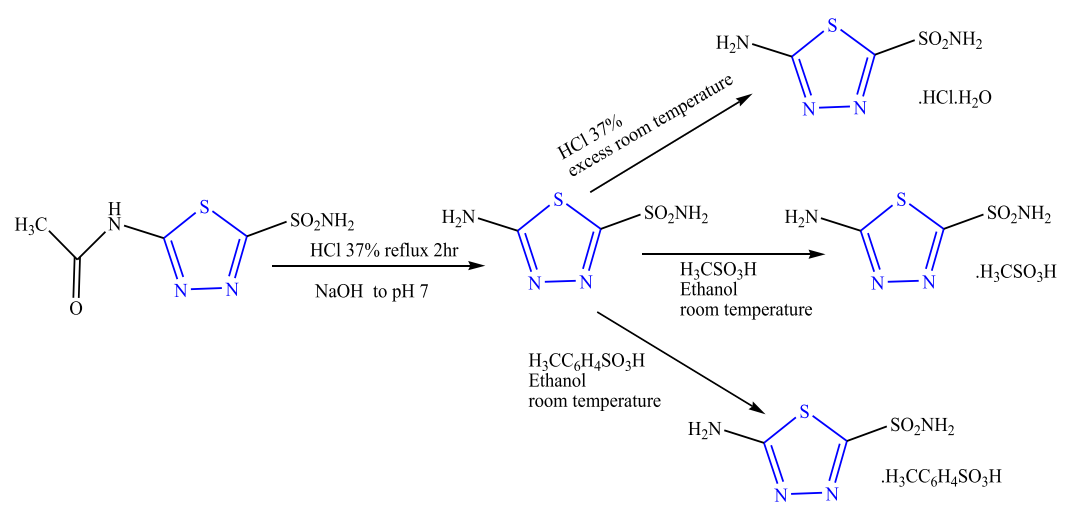

FIGURE 9 | Systematic scheme for synthesizing 5-amino-2-sulfonamide thiadiazole salts.

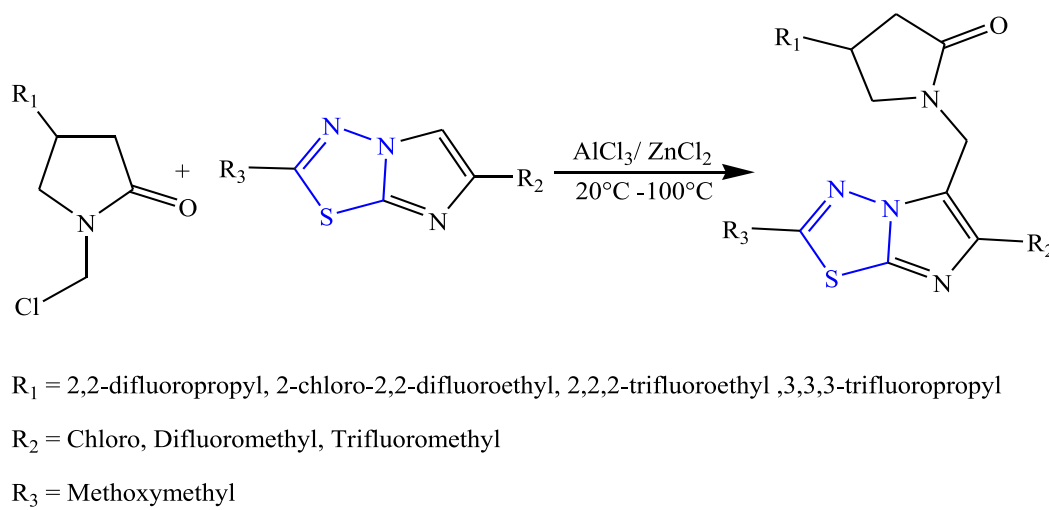

FIGURE 10 | Synthetic pathway for designing 2-oxo-1-pyrrolidinyl imidazothiadiazole derivatives.

benzyl thiol ring and $\mathrm{Br}$ substitution on the phenyl urea ring were responsible for good anticonvulsant activity. Two compounds named 1-\{5-[(2,4-dichlorobenzyl)thio]-1,3,4-thiadiazol-2-yl $\}$-3(4 fluorophenyl) urea $\left(\mathrm{ED}_{50}=2.70\right.$ and $0.65 \mu \mathrm{mol} / \mathrm{kg}$ ) and $1-$ \{5-[(3-methoxybenzyl)thio]-1,3,4-thiadiazol-2-yl\}-3-phenylurea $\left(\mathrm{ED}_{50}=2.72\right.$ and $\left.1.14 \mu \mathrm{mol} / \mathrm{kg}\right)$ were found to be highly potent in sleep and MES test compared with the standard (Toolabi et al., 2020).

A series of amide thiadiazole-linked valproic acid analog was synthesized by Malygim et al. (Figure 6) and confirmed the structure using IR, NMR $\left({ }^{1} \mathrm{H},{ }^{13} \mathrm{C}\right)$, and MS while the purity was checked by using the TLC and HPTLC methods. The in-vivo anticonvulsant activity was checked using MES and pentylenetrazole-induced model in mice taking isoniazid and pentylenetetrazole as standard. It is concluded that the synthesized compound [N-(5-ethyl-1,3,4-thiadiazol-2yl)-2-propyl pentane amide] when injected intraperitoneally was found to be 1.8 times more effective $\left(\mathrm{LD}_{50}\right)$ than valproic acid, $\mathrm{ED}_{50}$ was $126.8 \mathrm{mg} / \mathrm{kg}$, and the therapeutic index was found to be 7.3. The synthesized compound was found to be most effective for isoniazid-induced seizures (Malygin et al., 2020).

A two-step reaction was carried out to synthesize several quinazolinone derivatives of 1,3,4-thiadiazole by reacting with 2-substituted benzoxazin-4-one by Bhattachara et al. (Figure 7). The spectral analysis of the synthesized compound was done, and in-vivo anticonvulsant activity was checked by scPTZ and MES models, taking phenytoin and carbamazepine as standard out of which four compounds were found most active. The compound named (E)-3-(5-\{[(4-chlorophenyl)amino $]$ methyl $\}$ 1,3,4thiadiazol-2-yl)-2-styryl quinazoline-4(3H)-one showed the highest potency at $30 \mathrm{mg} / \mathrm{kg}$ within $30 \mathrm{~min}$. The SAR studies concluded that compounds containing nitro and chloro groups displayed potent anticonvulsant activity (Bhattacharya et al., 2019).

Several 1,3,4-thiadiazole derivatives were synthesized by condensing 3-amino-4-hydroxybenzoate along with ethanol to obtain the main compound (Figure 8) by Sarafroz et al. The characterization of the synthesized compound was done by NMR and IR and its in-vivo anticonvulsant activity was checked by 

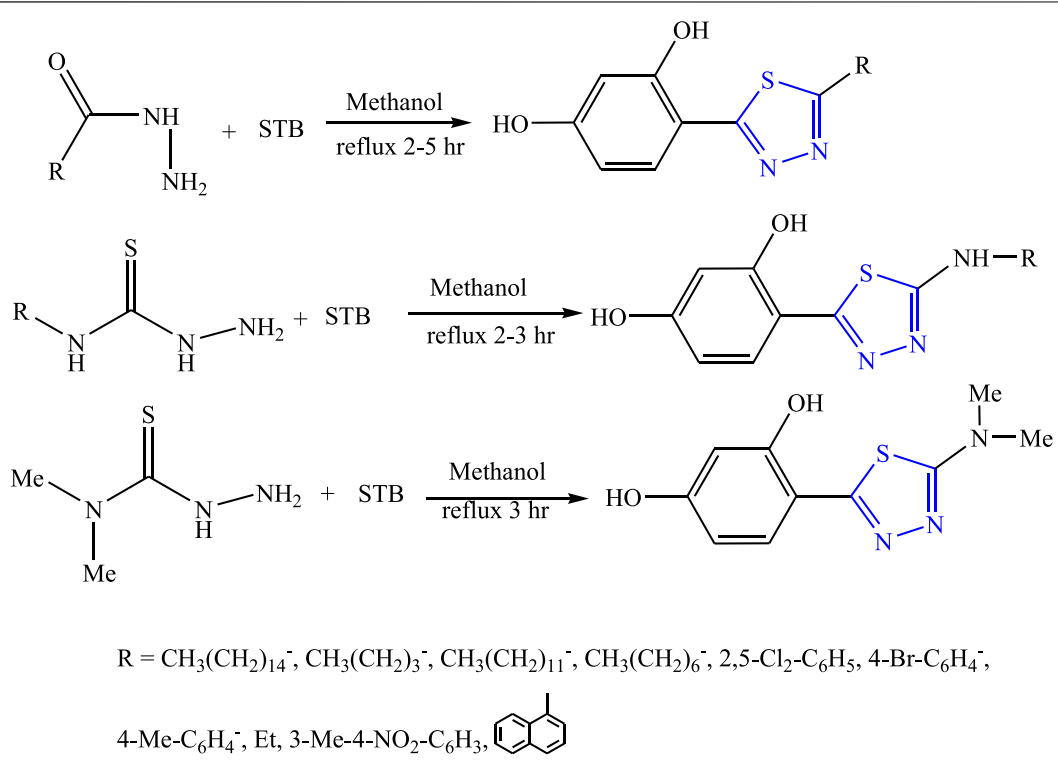

$\mathrm{STB}=\underbrace{\mathrm{S}}_{\mathrm{OH}}$

FIGURE 11 | Synthetic pathway for designing thiosemicarbnyl/hydrazide derivatives of 1,3,4-thiadiazole.

scPTZ and MES models, and for determining the neurotoxicity the rotarod method was used, although all compounds $(1,2,4-$ triazole-1,3,4-thiadiazoles substituted amino derivatives) showed good anticonvulsant activity; three compounds were found to be highly potent at $30 \mathrm{mg} / \mathrm{kg}$ within $30 \mathrm{~min}$. SAR activity revealed that the aldehyde and hydroxy-substituted groups showed potent activity (Sarafroz et al., 2019).

A two-step reaction was performed to synthesize three different salts of thiadiazole using acetazolamide as a precursor in the presence of $\mathrm{HCl}$ and $\mathrm{NaOH}$ using ethanol as a solvent (Figure 9) by Diaz et al. The characterization of the synthesized compound was done by spectroscopic techniques, and its in-vivo anticonvulsant activity was checked by intraperitoneally induced seizure using nikethamide and picrotoxins as standard. Neurotoxicity was determined by the rotarod method taking phenobarbital as the standard. In-silico studies were also performed in Hats. tosylate protein. It concluded that 5-amino-2-sulfonamide thiadiazole showed $72 \%-79 \%$ protection at $90 \mathrm{mg} / \mathrm{kg}$ against both the standard used when compared with its synthesized salts with no neurotoxicity; good binding affinity toward the selected protein by inhibiting carbonic anhydrase was also observed and was found effective against mild convulsions (Diaz et al., 2016).

Several new 2-oxo-1-pyrrolidinyl imidazothiadiazole derivatives were synthesized by Quesnel et al. using Lewis acid as a reagent (Figure 10). The characterization of synthesized compounds was done by spectral analysis, and the compounds were screened for their in-vivo anticonvulsant profile using sound-susceptible mice (audiogenic seizures), $\mathrm{Hz}$ seizure model, and PTZ models. Although all the synthesized compounds showed good anticonvulsant activity, a compound named 4-(2,2-difluoropropyl)-1-\{[2-(methoxymethyl)6(trifluoromethyl) imidazo (2,1b) $(1,3,4)$ thiadiazol-5-yl] methyl\} pyrrolidine- 2 one showed $95 \%$ anticonvulsant activity at the lowest dose by binding with SV2 protein. The SAR activity concluded that the addition of the $\mathrm{F}$ group increases the anticonvulsant activity of the synthesized compound (Quesnel et al., 2015).

Luszcksi et al. synthesized 13 new derivatives of 1,3,4thiadiazol by refluxing thiosemicarbnyl/hydrazides and STB \{sulfinylbis [(2,4-dihydroxyphenyl) methanethione $]\}$ in methanol (Figure 11). The characterization of synthesized compounds was done by the spectral analysis, and the compounds were screened for their in-vivo anticonvulsant profile by MES models using valproic acid as the standard drug. The SAR activity revealed that the substitution of long aliphatic chains with the ring either decreased the activity or showed no activity. Further, it concluded that only two compounds were found to be potent out of which 5-butyl-2(2,4-dihydroxyphenyl)-1,3,4-thiadiazole $\quad\left(\mathrm{ED}_{50}=247\right.$ $>500 \mathrm{mg} / \mathrm{kg}$ within $15 \mathrm{~min}$ ) was found to be a highly potent compound (Luszczki et al., 2014).

Some new thiadiazole derivatives (Figure 12) were synthesized by refluxing compound 1) and hydrazine hydrate (ethanolic solution) to form compound 2), then to the reaction mixture carbon disulfide and acetylacetone were added to form compound 3), then the equimolar quality of chloroacetyl chloride 

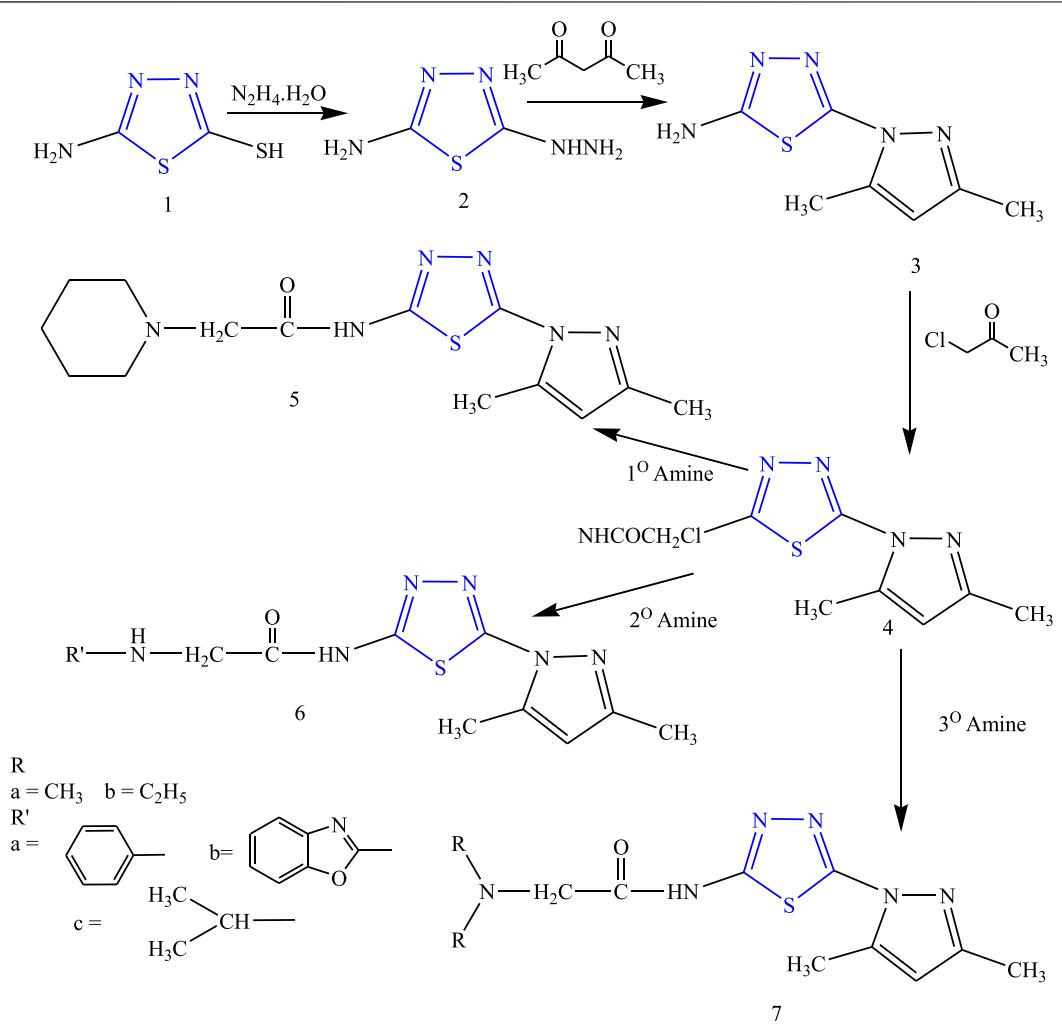

FIGURE 12 | Synthetic pathway for designing amide 1,3,4-thiadiazole derivatives.

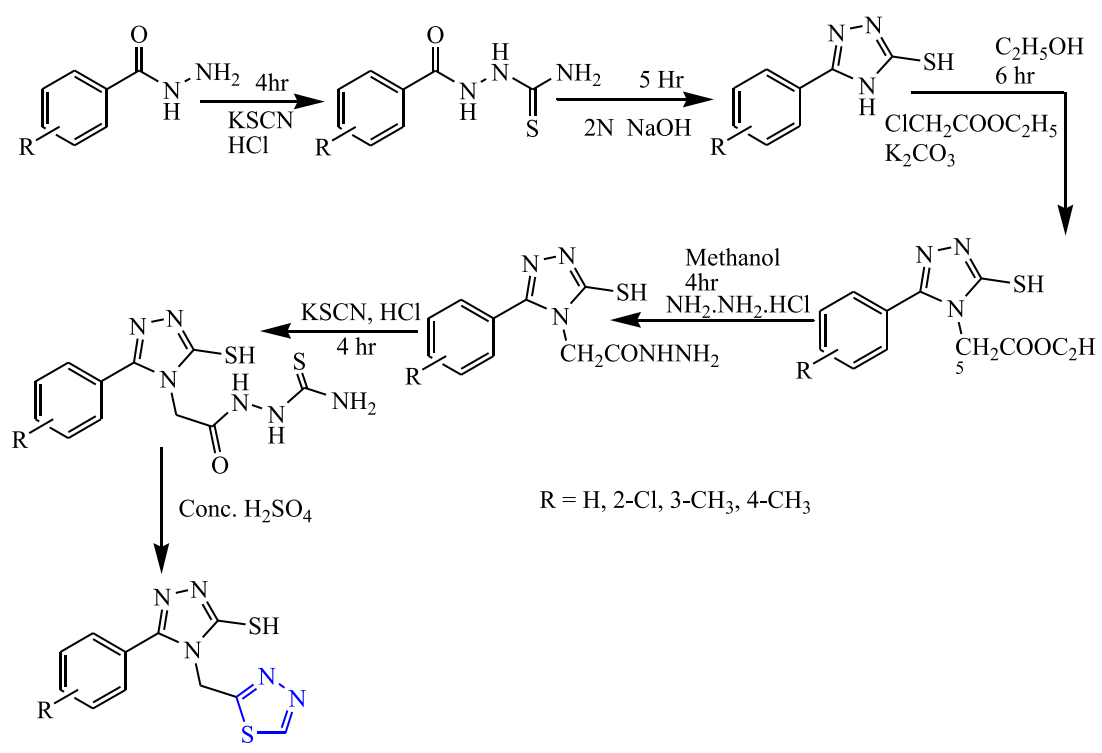

FIGURE 13 | Systematic scheme for synthesizing compounds by substituting 1,3,4-thiadiazole with Phenyl hydrazides and Benzoic acid. 


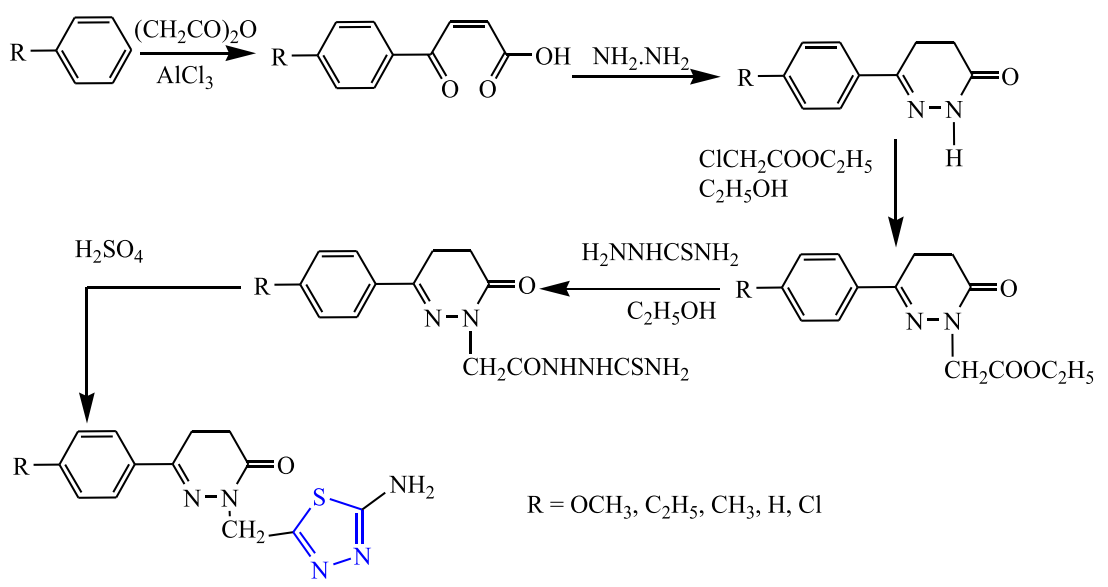

FIGURE 14 | Systematic scheme for synthesizing 5-amino-1,3,4-thiadiazole derivatives.

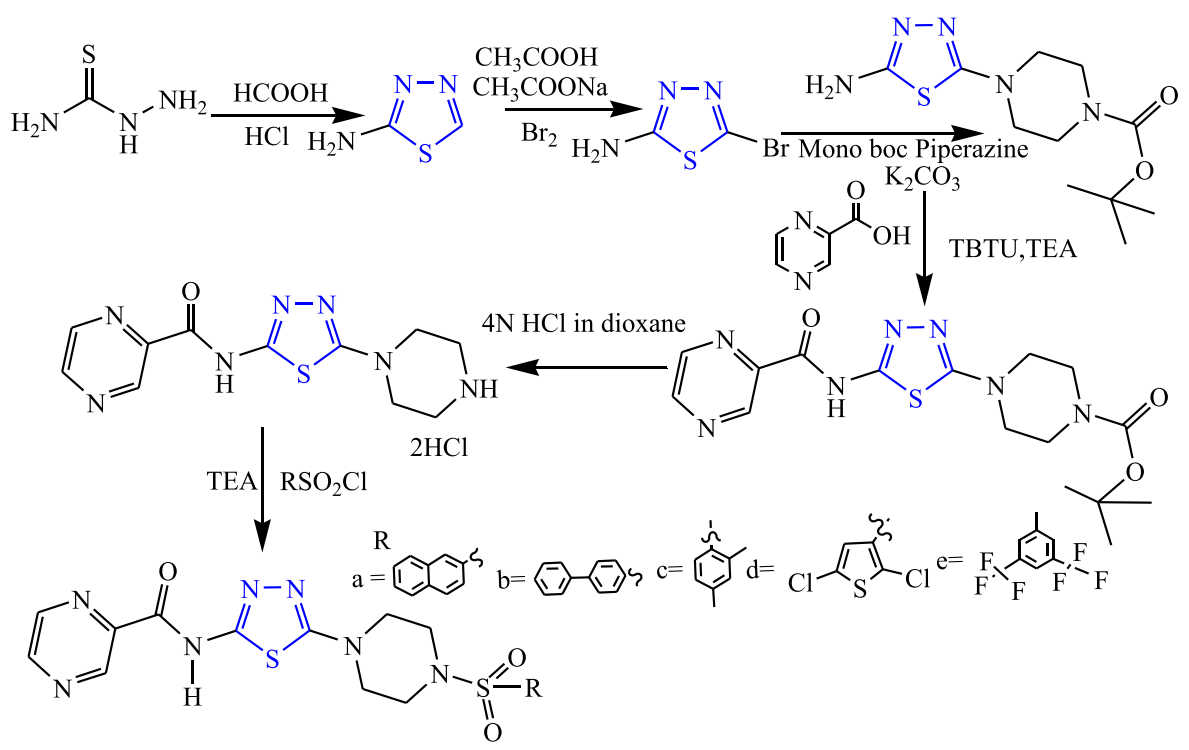

FIGURE 15 | Systematic scheme for synthesizing substituted 1,3,4-thiadiazole pyrazines derivatives.

was added to form the acetamide complex 4) which acts as the main intermediate, to which the equimolar amount of ethanolic solution of primary, secondary, and tertiary amine was added; their anticonvulsant activity was reported by Rahman et al. After spectral analysis, the synthesized compounds were screened for their anticonvulsant profile on albino mice. Although all the synthesized compounds showed good anticonvulsant activity, a compound named 2-(diethylamino)-N-(3,5-dimethyl-1Hpyrazol1-yl)-1,3,4-thiadiazole-2-yl acetamide exhibited $50 \%$ or more prominent activity against induced convulsion at a lower dose of $30 \mathrm{mg} / \mathrm{kg}$ at $30 \mathrm{~min}$. It concluded that the lipophilic nature of the ring is responsible for the activity (Rahman et al., 2014).
Several 1,3,4-thiadiazole derivatives were synthesized from substituted phenyl hydrazides and substituted benzoic acid using alcohol and water as a solvent (Figure 13) by Kumudha et al. The characterization of synthesized compounds was done by spectral analysis, and the compounds were screened for their invivo anticonvulsant profile using PTZ and MES models. All the synthesized compounds were found to be potent, but compounds named 4-[(1,3,4-thiadiazol-2-yl)methyl]-5-p-tolyl-4H-1,2,4triazole-3-thiol showed good activity during the PTZ and MES tests ( $83 \%$ and $75 \%$ inhibition) at $20 \mathrm{mg} / \mathrm{kg}$ with less toxicity. It concluded that the electron-substituted group showed better anticonvulsant activity (Kumudha et al., 2014). 


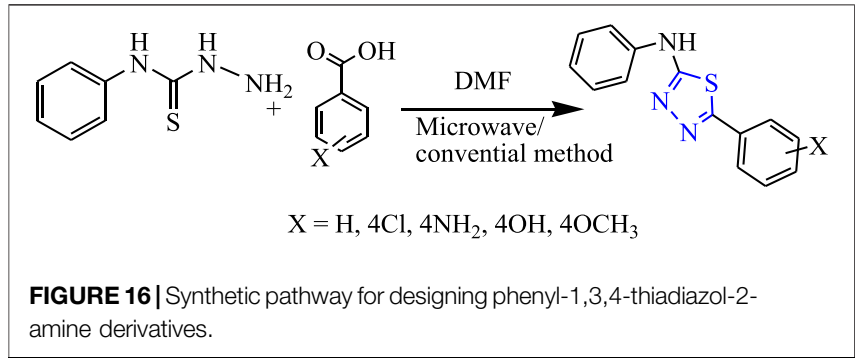

Several 1,3,4-thiadiazole derivatives were synthesized by Sharma et al. Friedel craft acylation was done to obtain the intermediate b-aroyl propionic acid, aluminum chloride, and $\mathrm{C}_{4} \mathrm{H}_{4} \mathrm{O}_{3}$ which were further treated with hydrazine hydrate from pyridazine and then treated with ethyl chloroacetate to form acetic acid ethyl ester, then thiosemicarbazide was added and on stirring to form hydrazine carbothioamide, and then it was treated with concentrated sulfuric acid to synthesize the final compound (Figure 14). Their characterization of synthesized compounds was done by NMR, IR, and mass spectral analyses, and the in-vivo anticonvulsant activity was checked by MES and scPTZ models taking diazepam as standard out of which two compounds were found most active. The compound named $\{2-$ [(5-amino-1,3,4-thiadiazol-2-yl)methyl]-6-(4chlorophenyl)-4,5dihydropyridine-3(2H)-one showed $85.44 \%$ inhibition in both scPTZ $(100 \mathrm{mg} / \mathrm{kg})$ and MES $(50 \mathrm{mg} / \mathrm{kg})$ tests; it further concluded that the $\mathrm{Cl}$ substituent compound was found to be effective (Sharma et al., 2014).

Several derivatives of substituted 1,3,4-thiadiazole pyrazine were synthesized by Kikkeri et al. (Figure 15). They evaluated in-vivo anticonvulsant activity using the MES method, and neurotoxicity was checked using the rotarod method taking phenytoin as standard. Two compounds named $\mathrm{N}$-(5-\{4-[(2,5-dichlorothiophen-3-yl)sulfonyl] piperazine1-yl\}-1,3,4-thiadiazole-2-yl)pyrazine-2-carboxamide

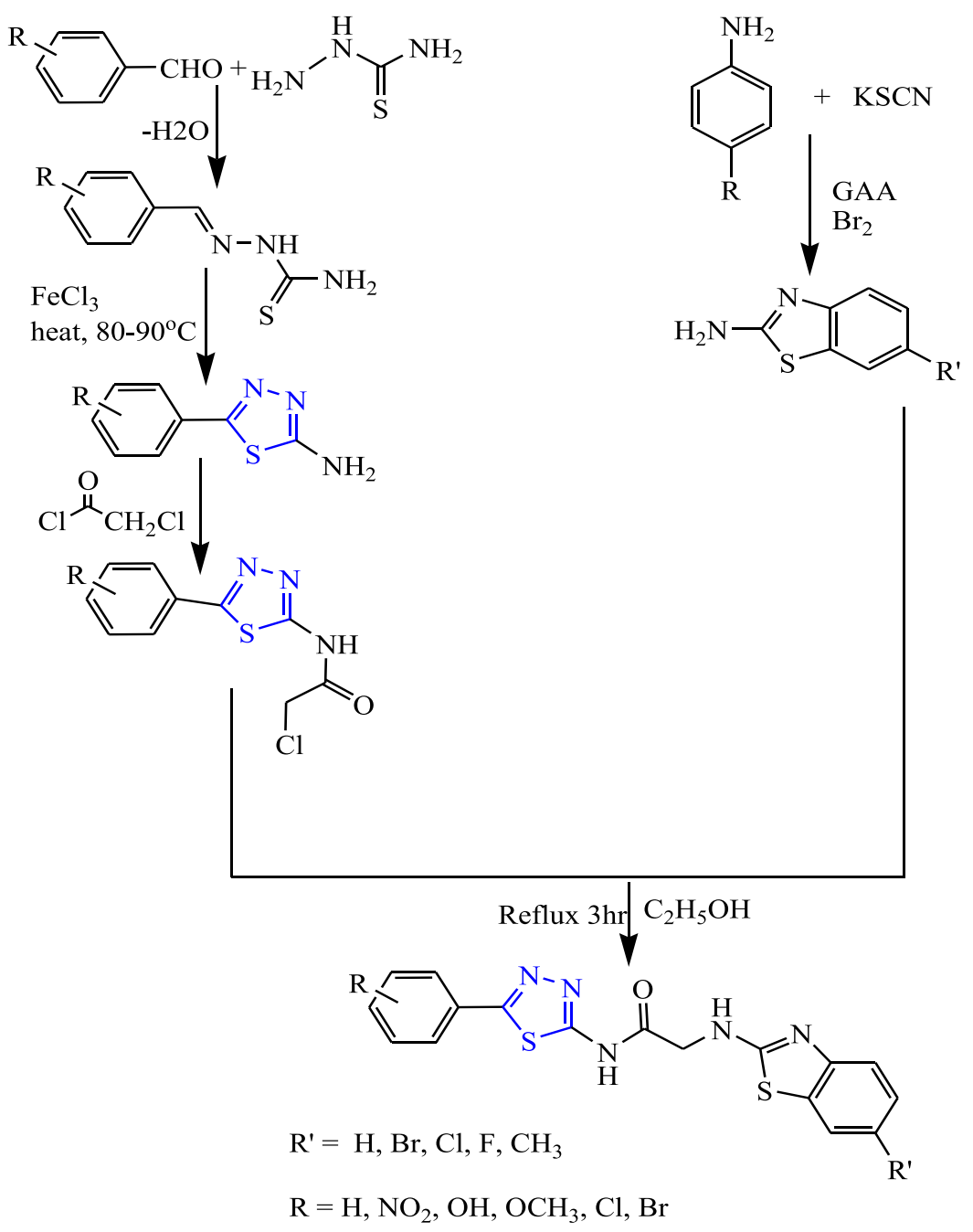

FIGURE 17 | Systematic scheme for synthesizing 1,3,4-thiadiazol-acid-amide derivatives. 
<smiles>CCOC(=O)Cn1c(C)nc2cc(C(N)=C(N)C(=O)OCc3ccccc3)ccc2c1=O</smiles>

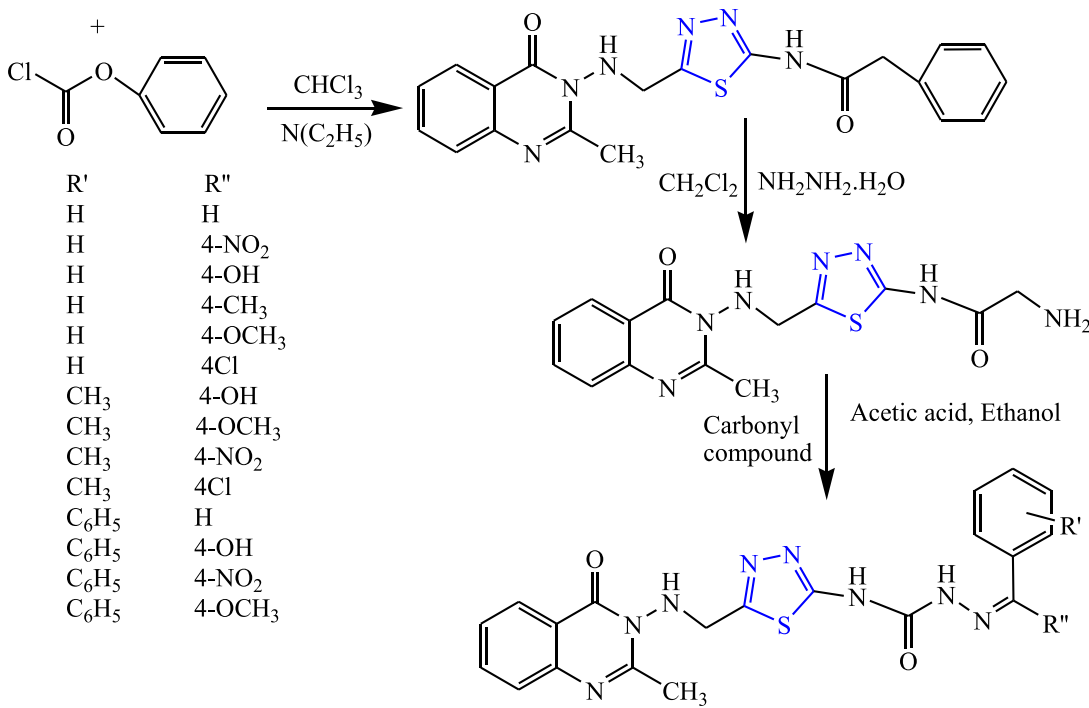

FIGURE 18 | Systematic scheme for synthesizing 1,3,4-thiadiazole quinazoline analogs.

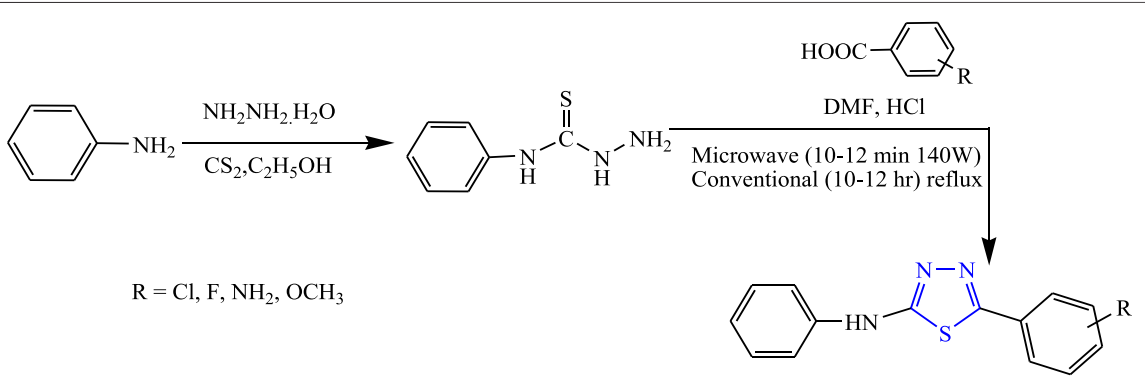

FIGURE 19 | Synthetic pathway for designing phenyl-1,3,4-thiadiazol-2-amine derivatives.

(74.52\% inhibition) and $\mathrm{N}-(5-(4-\{[3,5$ bis (trifluoromethyl) phenyl $]$ sulfonyl\} piperazine-1-yl)-1,3,4-thiazol-2-yl) pyrazine-2-carboxamide (74.88\% inhibition) were found to be active. The SAR study of these compounds indicated that more anticonvulsant activity is observed when the phenyl ring is introduced as compared to the methyl group (Kikkeri et al., 2013).

Sahoo et al. synthesized 1,3,4-thiadiazole derivatives by both conventional and microwave-irradiated methods (Figure 16). The microwave method was more effective and gave a high yield. The characterization of compounds that were newly synthesized was done by ${ }^{1} \mathrm{H}$ NMR, IR, and LC-mass, and an in-vivo study was done by the MES method while a neurotoxicity study was done by the rotarod test using phenytoin as a standard compound. Compounds substituted by the $\mathrm{OCH}_{3}$ group [5-(3methoxyphenyl)-N-phenyl-1,3,4-thiadiazol-2-amine] were found to be highly effective; it showed $19.64 \%$ protection at a low dose $(30 \mathrm{mg} / \mathrm{kg})$ and $64.28 \%$ protection at a high dose $(300 \mathrm{mg} / \mathrm{kg})$ with no toxicity. Molecular docking was performed targeting voltage-gated channels using Glide XP software (Sahoo et al., 2013).

Several Schiff-base 1,3,4-thiadiazol-acid-amide derivatives (Figure 17) were synthesized by Siddiqui et al. An important 


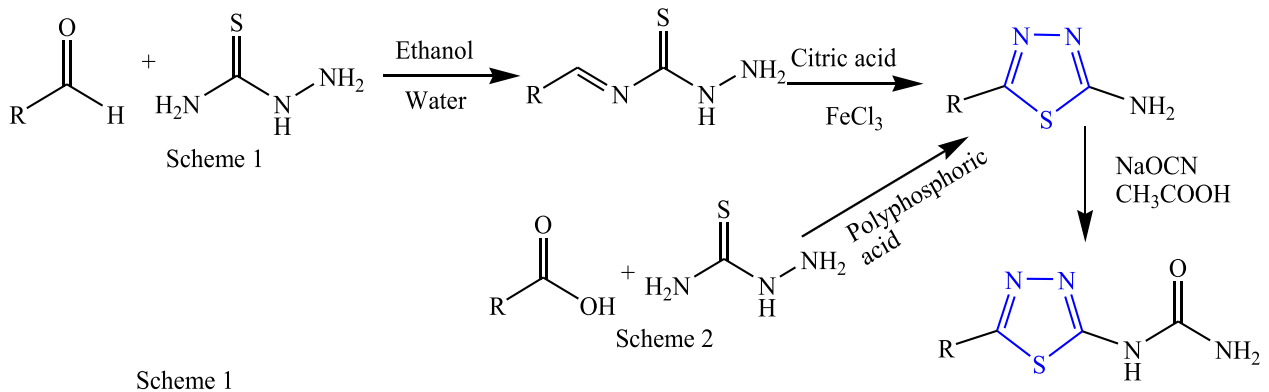

Scheme 1

$\mathrm{R}=\mathrm{C}_{6} \mathrm{H}_{5}, \mathrm{C}_{7} \mathrm{H}_{6} \mathrm{O}, \mathrm{C}_{6} \mathrm{H}_{5} \mathrm{O}, \mathrm{C}_{4} \mathrm{H}_{3} \mathrm{O}, \mathrm{C}_{8} \mathrm{H}_{7}, \mathrm{C}_{8} \mathrm{H}_{9} \mathrm{O}_{2}, \mathrm{C}_{8} \mathrm{H}_{10} \mathrm{~N}$

Scheme 2

$\mathrm{R}=\mathrm{C}_{6} \mathrm{H}_{4} \mathrm{NO}_{2}, \mathrm{C}_{6} \mathrm{H}_{4} \mathrm{Cl}, \mathrm{C}_{6} \mathrm{H}_{3} \mathrm{C}_{2}$

FIGURE 20 | Systematic scheme for synthesizing aryl-substituted 1,3,4-thiadiazole analog

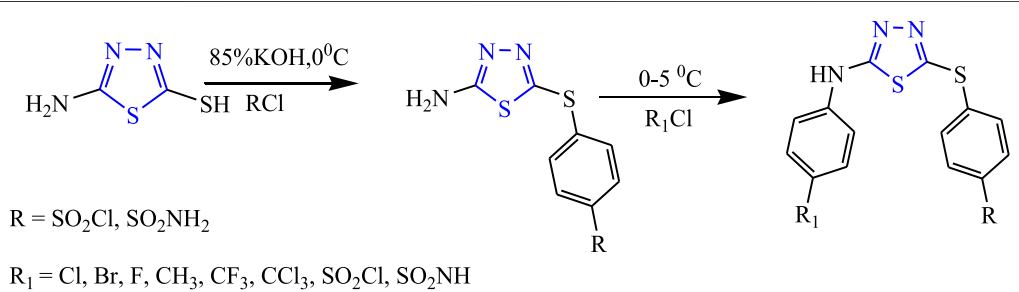

FIGURE 21 | Systematic scheme for synthesizing amino 1,3,4-thiadiazole analogs.

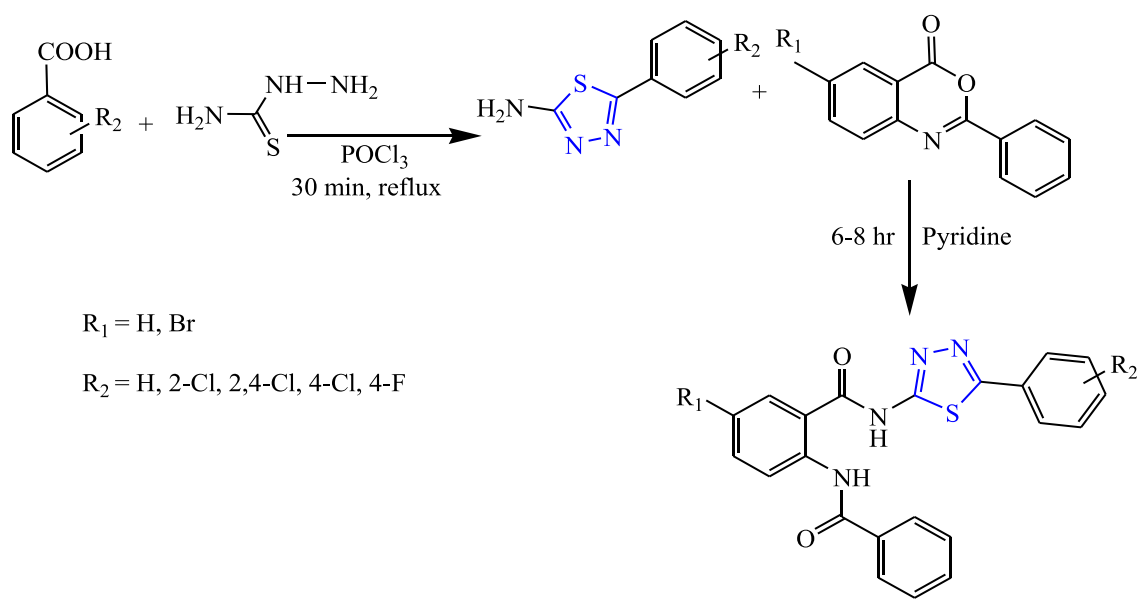

FIGURE 22 | Systematic scheme for synthesizing carboxamide 1,3,4-thiadiazole derivatives.

role was played by the benzothiazole hydrophobic domain through amino acetamide linkage for anticonvulsant activity. The synthesized compounds were characterized by spectral analysis; an in-vivo activity was studied by the MES method, and a neurotoxicity study was done by the rotarod method using phenytoin as a standard compound. Two compounds 2-[(6-fluoro-1,3-benzothiazole-2-yl)amino]-N-[5-(4-nitrophenyl)1,3,4-thiadiazol-2-yl] acetamide and $\mathrm{N}$-[5-(4-methoxyphenyl)1,3,4-thiadiazol-2-yl]-2-[(6-methyl-1,3-benzothiazole-2-yl)amino] acetamide were found to be highly effective as they showed $100 \%$ 


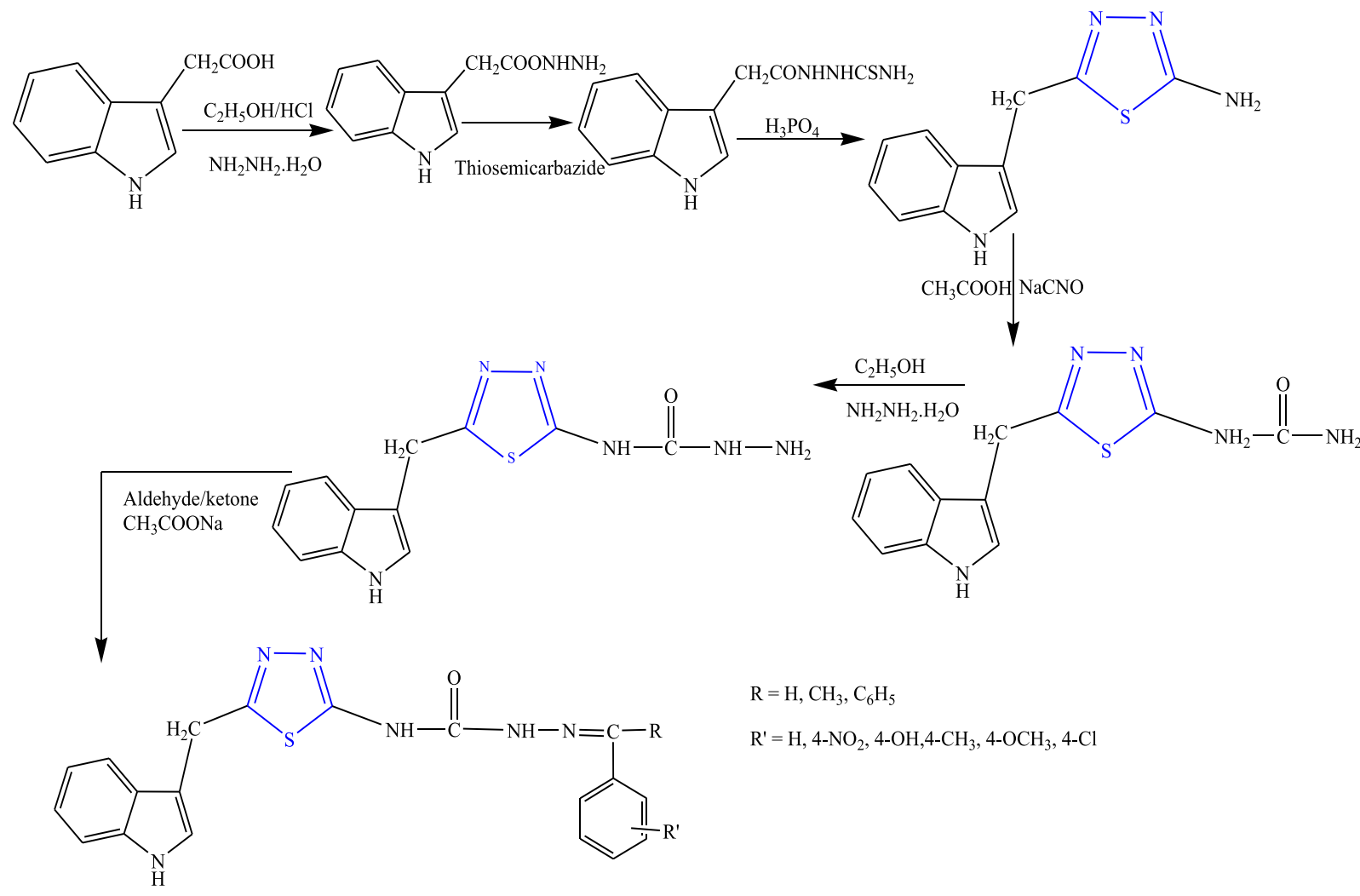

FIGURE 23 | Synthetic pathway for designing 1,3,4-thiadiazoles derivatives.

protection at a low dose $(30 \mathrm{mg} / \mathrm{kg})$ with no toxicity at a low dose $(30 \mathrm{mg} / \mathrm{kg})$ at $30 \mathrm{~min}$ (Siddiqui et al., 2013).

Rajak et al. synthesized semi-carbazones from 3-amino-2methyl quinazoline-4(3H)-ones by refluxing them for $6-8 \mathrm{~h}$ (Figure 18). The characterization of newly designed compounds was done by IR and NMR, and in-vivo activity was studied using PTZ and MES models. Although all the compounds were found to be potent, N-(5-(\{[2-methyl-4oxoquinazolin-3(4H)-yl] amino\} methyl)-1,3,4-thiadiazol-2-yl)$\mathrm{N}^{4}$-[1-(4nitrophenyl) (phenyl) methanone]-semicarbazone was found to be highly potent for both models $(100 \mathrm{mg} / \mathrm{kg}$ for MES and $300 \mathrm{mg} / \mathrm{kg}$ for PTZ). The SAR study of the synthesized compounds concluded that the p-substituted group present in aryl moiety changes variation on the activity (anti-convulsion) of the test compounds and a compound containing the methyl group showed potent activity while the compound substituted with chloro and nitro groups displayed the highest potency (Rajak et al., 2012).

Several new derivatives of 1,3,4-thiadiazole were synthesized by Sahoo et al. by both microwave-irradiated and conventional methods. Cyclization of various aromatic acids with $\mathrm{N}$-phenyl thiosemicarbazide was done to obtain the main compounds (Figure 19). The microwave method was more effective and gave a high yield. The synthesized compounds were characterized by spectral analysis, and an in-vivo study was done using the MES model in rats. 5-(4-Methoxyphenyl)-N-phenyl-1,3,4-thiadiazol-
2 -amine showed maximum protection $(64.28 \%)$ at $300 \mathrm{mg} / \mathrm{kg}$ (Sahoo et al., 2012).

Several new 1,3,4-thiadiazole derivatives were designed by Gowramma et al. first by doing oxidative cyclization of thiosemicarbazone and citric acid to get the intermediate, and then the final compound was obtained by adding sodium cyanate in glacial acetic acid using ethanol and water as a solvent and refluxing at $80^{\circ} \mathrm{C}-90^{\circ} \mathrm{C}$ for $45 \mathrm{~min}$ (Figure 20). The characterization of synthesized compounds was done by NMR and IR, and in-vivo anticonvulsant activity was checked by subcutaneous pentylenetetrazole (scPTZ) taking phenytoin as standard. A compound containing nitro and chloro groups showed prominent anticonvulsant activity at $100 \mathrm{mg} / \mathrm{kg}$ (Gowramma et al., 2012).

Several 1,3,4-thiadiazole analogs were synthesized from an amino 1,3,4-thiadiazole derivative by Sharma et al. (Figure 21) by stirring $85 \% \mathrm{KOH}$ solution and 4-chloro benzene sulfonamide at $0^{\circ} \mathrm{C}$ and $5^{\circ} \mathrm{C}$, and then the intermediate was added to obtain the final compound using ether. The characterization of the design compounds was done by spectral analysis, and their in-vivo study was done using PTZ and MES; five compounds showed good anticonvulsant activity, but the compound named 4-[5-(4-trifluoromethylphenylamino)-(1,3,4)thiadiazol-2-ylsulfanyl]-benzene sulfonyl chloride showed $66.6 \%$ inhibition in the MES model and zero death in the PTZ model (Sharma et al., 2011). 


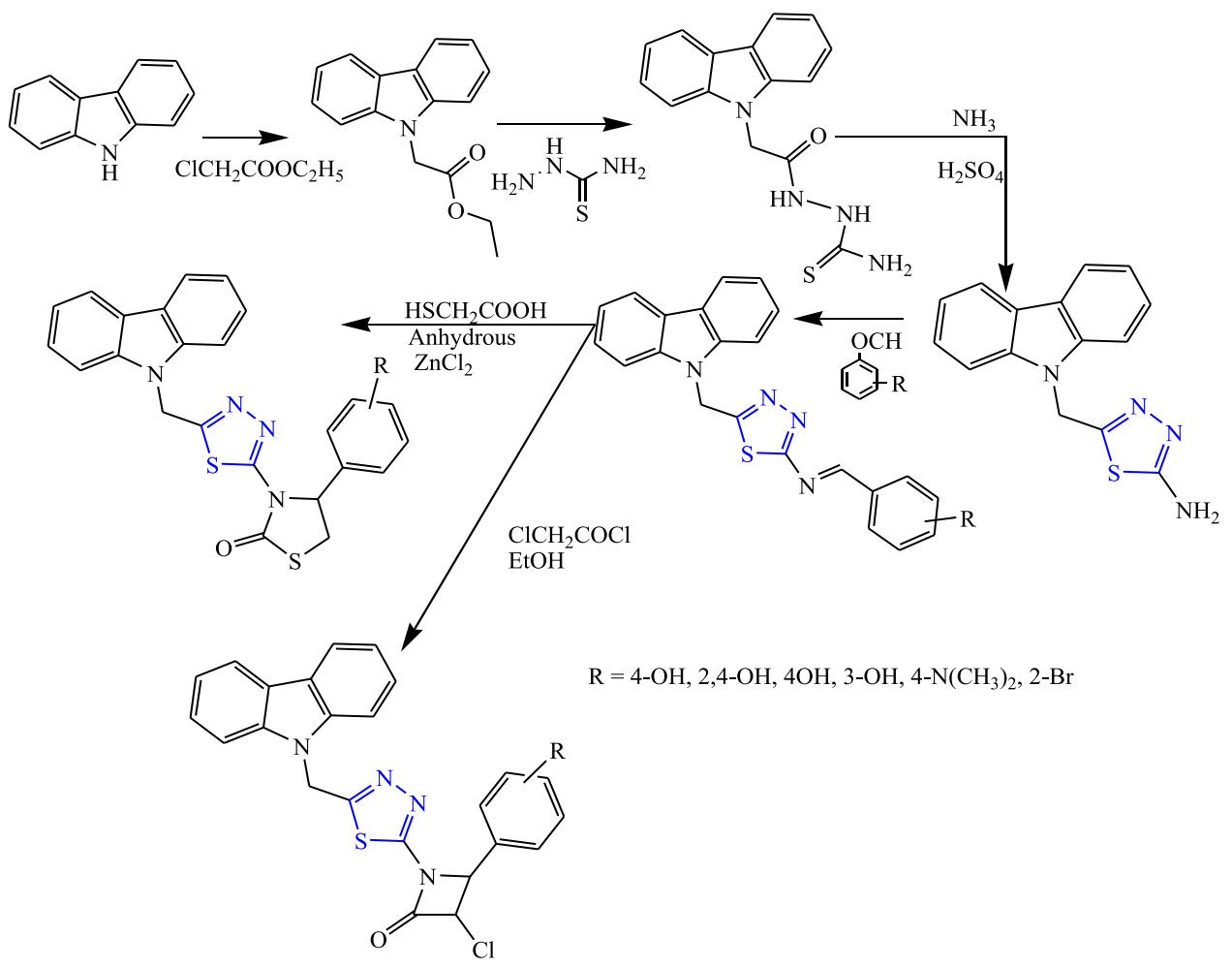

FIGURE 24 | Systematic scheme for synthesizing thiadiazolylazetidinonyl carbazole derivatives.

Several analogs of 1,3,4-thiadiazoles containing carboxamide nucleus were synthesized by Masi et al. by condensing 2,5disubstituted-1,3,4-thiadiazole with benzoxazine (Figure 22). The characterization of the design compounds was done by spectral analysis, and in-vivo study was done using the PTZ model taking carbamazepine as standard. Although all the compounds showed good results, the bromo-substituted compounds were found to be potent especially 2-benzamide-5bromo-N-[5-(2-chlorophenyl)-1,3,4-thiadiazol-2-yl] benzamide showed $100 \%$ protection at $60 \mathrm{mg} / \mathrm{kg}$ for mortality $(1-24 \mathrm{~h})$; therefore, it is concluded that substitution with $\mathrm{Br}$ increases the activity of the compound (Masi et al., 2011).

Rajak et al. designed di-substituted derivatives of 1,3,4thiadiazoles (Figure 23). The characterization of the synthesized compounds was done by spectral analysis, in-vivo study was done using the PTZ and MES methods, and neurotoxicity was checked by the rotarod test. Among the synthesized compounds, one compound named $\mathrm{N}^{1}-[5-(1 \mathrm{H}-$ indol-3-ylmethyl)-1,3,4-thiadiazol-2yl]- $\mathrm{N}^{4}$-[1-(4-hydroxyphenyl) (phenyl) methanone] semicarbazone was found to be the most potent compound as it was effective for both PTZ $(300 \mathrm{mg} / \mathrm{kg})$ and MES $(100 \mathrm{mg} / \mathrm{kg})$ methods without any neurotoxicity. The SAR study reveals that if the nitro group and the hydroxy group are introduced on the phenyl ring, it showed high-potency in-vivo tests (Rajak. et al., 2010).

Several substituted thiadiazolylazetidinonyl carbazole derivatives were synthesized by Kaur et al. (Figure 24). The characterization of the synthesized compounds was done by spectral analysis, and in-vivo study was done using the PTZ and MES methods. The neurotoxicity of the compounds was checked using the rotarod test. Only one compound $(3-\{5-[(9 \mathrm{H}-$ carbazol-9-yl) methyl]-1,3,4-thiadiazol-2-yl\}-4-(3-bromophenyl) thiazolidine-2-one) showed potent results at $40 \mathrm{mg} / \mathrm{kg}$ with $90 \%$ protection for the MES test $\left(\mathrm{LD}_{50}>1,600\right)$ (Kaur et al., 2010).

Several new derivatives of 5-cylohexylamino-1,3,4-thiadiazole were synthesized taking benzoyl chloride and ethyl 4aminobenzoate as precursors by Karakus et al. (Figure 25). The characterization of the compounds was done by IR and ${ }^{1} \mathrm{H}-\mathrm{NMR}$, and an in-vivo study was done using PTZ and MES methods. The SAR studies indicate that groups (chloro, allyl, methyl) attached to phenyl were responsible for increasing the activity of the compound. It concluded that although all the compounds showed good activity against petit mal seizures, the compound named N-\{4-[(5-cyclohexylamino)-1,3,4-thiadiazole2-yl]phenyl\}N9-(2-methylphenyl) thiourea showed the highest protection (68.42\%) at $25 \mathrm{mg} / \mathrm{kg}$ (Karakus et al., 2009).

Several derivatives of 1,3,4-thiadiazoles were synthesized from substituted acetophenones by Siddiqui et al. (Figure 26). The characterization of the compounds was done by spectral analysis, and an in-vivo study was done using PTZ and MES using phenytoin sodium as standard. Two compounds were found to be potent for the MES test, out of which $\mathrm{N}$-(4-chlorophenyl)- $\mathrm{N}^{5}$-[5,6-dichlorobenzo(d) thiazol-2-yl]-1,3,4-thiadiazole-2,5-diamine was found to be 


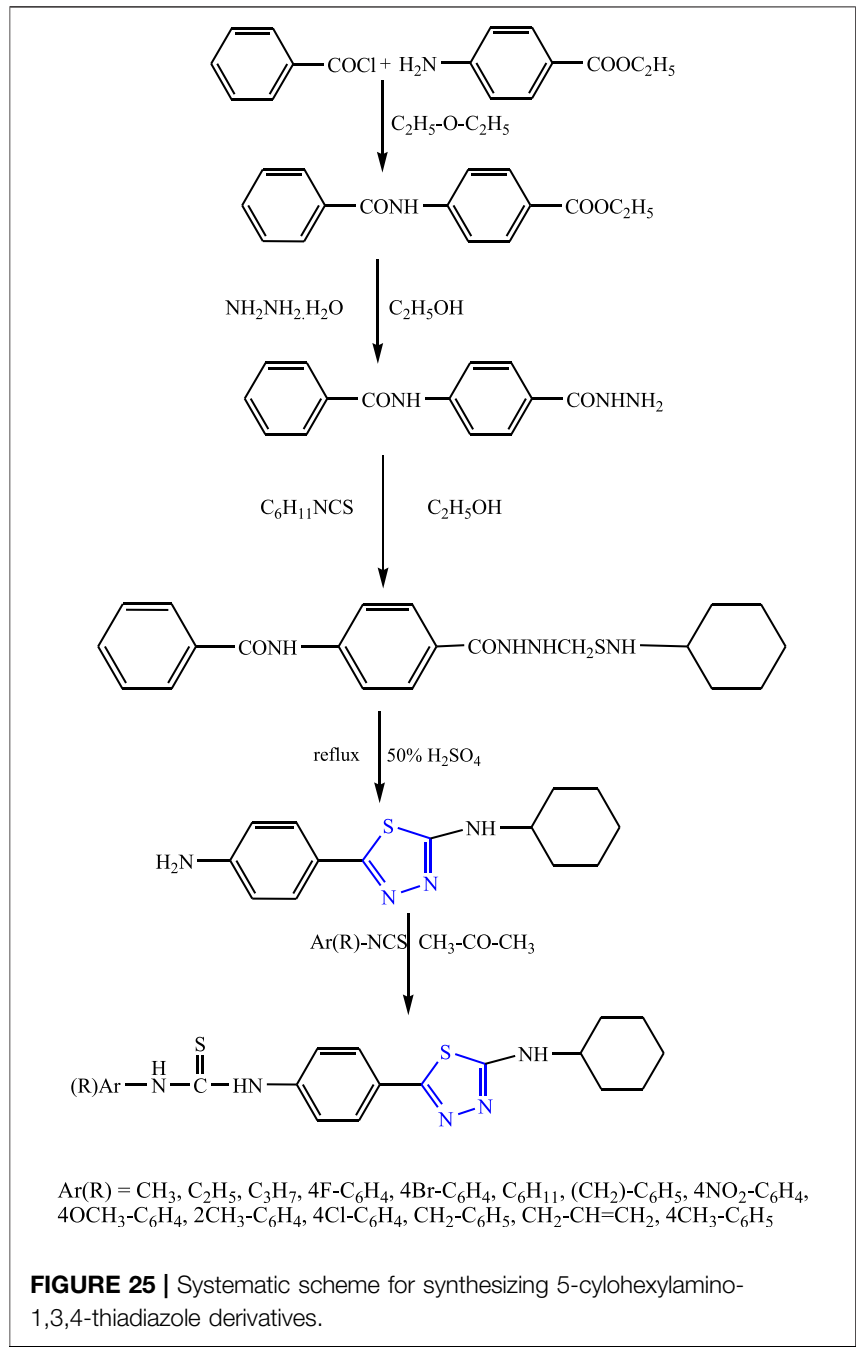

highly effective ( $100 \%$ protection at $30 \mathrm{mg} / \mathrm{kg}$ with no toxicity) It is concluded that the compound containing the halo group showed good anticonvulsant activity when compared to another group attached (Siddiqui et al., 2009).

Seven new thiadiazole derivatives were synthesized by Pattanayak et al. by dissolving 5-sulfanyl-1,3,4-thiadiazole-2arylamine in $85 \% \mathrm{KOH}$ solution and then stirring it for 5-10 min at room temperature, then the temperature was brought down to $0^{\circ} \mathrm{C}$. An equimolar amount of aromatic halide (R) was added with vigorous stirring to form an intermediate, then a mole intermediate was dissolved in distilled water while maintaining the temperature at $0^{\circ} \mathrm{C}-5^{\circ} \mathrm{C}$ with continuous stirring; to the reaction mixture, benzoyl chloride was added dropwise and the reaction was continued (Figure 27). The characterization of the compounds was done by spectral analysis, and an in-vivo study was done using the MES and PTZ methods. Three compounds showed significant anticonvulsant activity while one named 4-[5-benzoyl amino$(1,3,4)$-thiadiazole-2yl-sulfanyl]-benzene sulfonyl chloride out of the three showed the best activity at $25 \mathrm{mg} / \mathrm{kg}$ (Pattanayak et al., 2009).

Yar et al. reported a series of five-membered heterocyclic compounds with their anticonvulsant activity by refluxing isoniazid with equimolar substituted phenyl isothiocyanates using ethanol as a solvent for 5-6 h to form substituted phenylthiosemicarbazides, then $\mathrm{H}_{2} \mathrm{SO}_{4}$ was added, and continuous stirring was done at $0^{\circ} \mathrm{C}-5^{\circ} \mathrm{C}$ to form the main compound (Figure 28). The spectral analysis was done to confirm the structure of the compounds. 2-(4-Chlorophenyl) amino-5-(4-pyridyl)-1,3,4-thiadiazole was found to be highly potent during the evaluation by MES and PTZ methods as it contains the $\mathrm{Cl}$ group at the para position and showed $100 \%$ protection at a low dose $(25 \mathrm{mg} / \mathrm{kg}$ ) (Yar et al., 2009).

\footnotetext{
FIGURE 26 I Synthetic pathway for designing 1,3,4 thiadiazole derivatives.
} 


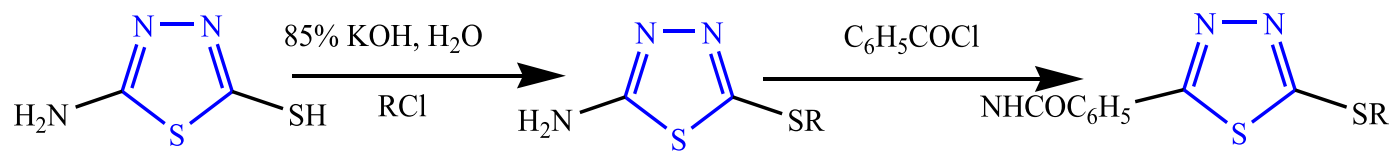

$\mathrm{R}=4-\mathrm{C}_{6} \mathrm{H}_{4} \mathrm{SO}_{2} \mathrm{Cl}, 4-\mathrm{C}_{6} \mathrm{H}_{4} \mathrm{SO}_{2} \mathrm{NH}_{2}, 4-\mathrm{C}_{6} \mathrm{H}_{4} \mathrm{CCl}_{3}, 4-\mathrm{C}_{6} \mathrm{H}_{4} \mathrm{CH}_{3}, 4-\mathrm{C}_{6} \mathrm{H}_{4} \mathrm{CF}_{3}, 4-\mathrm{C}_{6} \mathrm{H}_{4} \mathrm{Br}, 4-\mathrm{C}_{6} \mathrm{H}_{4} \mathrm{~F}$

FIGURE 27 | Systematic scheme for synthesizing amine-1,3,4-thiadiazole analog.

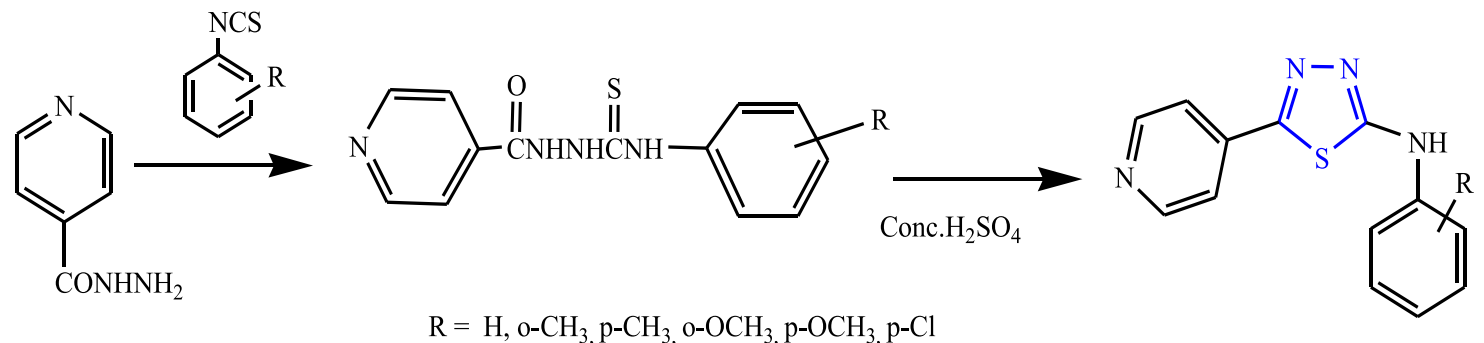

FIGURE 28 | Synthetic pathway for synthesizing new phenyl isothiocyanate 1,3,4-thiadiazole derivatives.
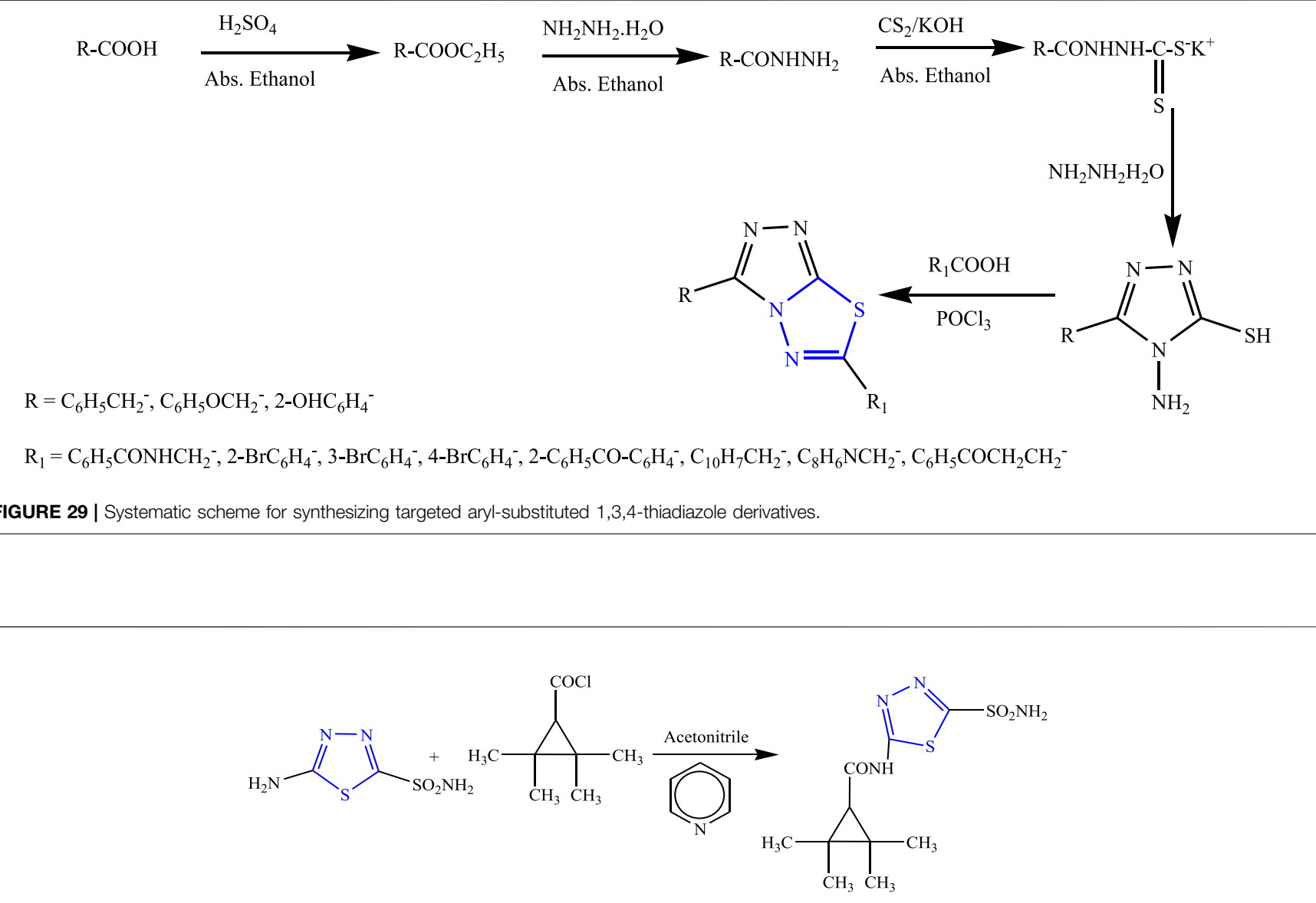

FIGURE 30 | Synthetic pathway for synthesizing new 1,3,4-thiadiazole-2-sulfonamide derivatives. 


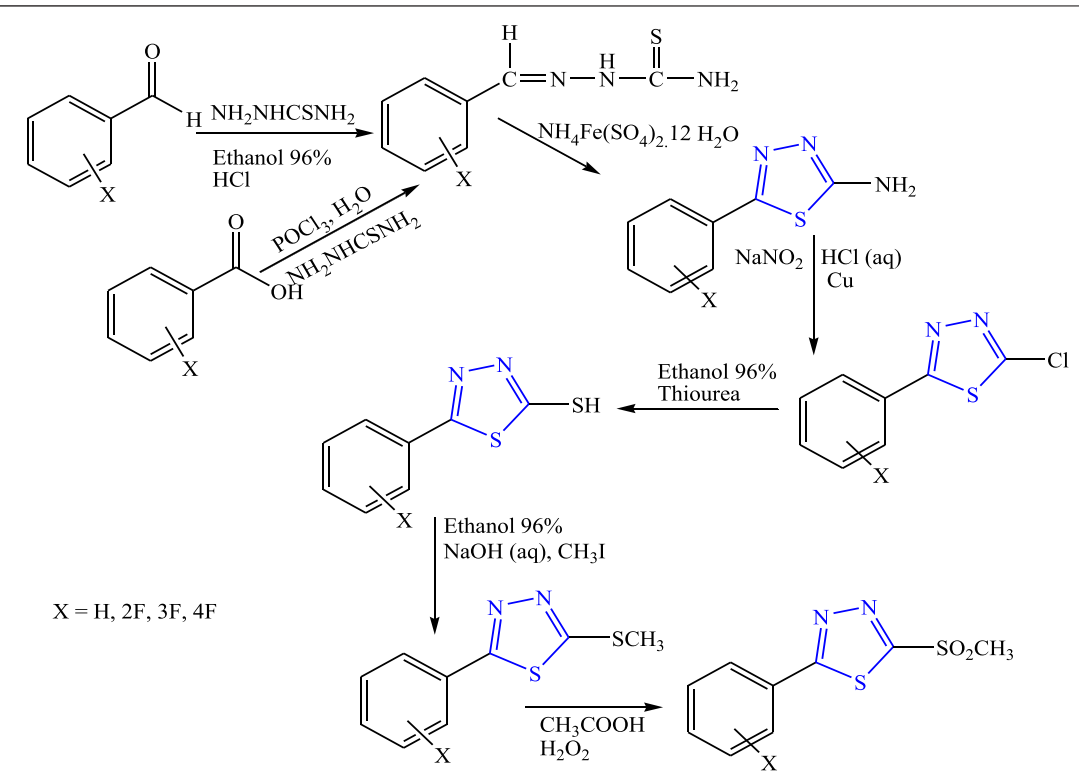

FIGURE 31 | Synthetic pathway for synthesizing new 5-aryl-1,3,4-thiadiazole derivatives

Twenty new derivatives of 1,3,4-thiadiazole were synthesized by Husain et al. The first esterification was done to form acid hydrazide, and then in the presence of potassium hydroxide, carbon disulfide, ethanol, and potassium dithiocarbamate were formed; further, $5 \mathrm{~h}$ reflux was done in the presence of aromatic acid to synthesize the main compounds (Figure 29). Spectral analysis was done to confirm the structure of the compounds, and their in-vivo anticonvulsant activity was checked by PTZ and MES models. Neurotoxicity was also determined taking phenytoin and carbamazepine as standard, out of which six compounds were found to be potent in the MES test while four compounds successfully passed the neurotoxicity test as the potent compounds contain halo-substituted aryl (bromophenyl) in the sixth position of the triazolothiadiazole ring which is essential for the anticonvulsant activity, as it showed great results at a low dose $(30 \mathrm{mg} / \mathrm{kg}$ within $1 / 2 \mathrm{~h})$ with no toxicity (Hussain et al., 2009).

5-(Tetramethyl cyclopropane carbonyl amido)-1,3,4thiadiazole-2-sulfonamide was synthesized by Bialer et al. using pyridine as solvent (Figure 30). Spectral analysis was done to confirm the structure of the compound, and in-vivo anticonvulsant activity was checked by the PTZ and MES models, while neurotoxicity was checked using the rotarod method. The synthesized compound showed the highest activity only in the MES model with no toxicity, and $\mathrm{ED}_{50}$ was found at the lowest dose $(16 \mathrm{mg} / \mathrm{kg}$ ) within $30 \mathrm{~min}$ (Bialer et al., 2007).

Foroumadi et al. synthesized 5-aryl-1,3,4-thiadiazole derivatives (Figure 31). Spectral analysis was done to confirm the structure of the compounds, and in-vivo anticonvulsant activity was checked by the PTZ method taking diazepam and flumazenil as standard. It is concluded that the amino-substituted compound $\left(\mathrm{LD}_{50}>500 \mathrm{mg} / \mathrm{kg}\right.$ ) showed anticonvulsant activity while the ring substituted with other derivatives such as mercapto and methyl sulfone either showed no activity or occurrence of convulsion (Foroumadi et al., 2000).

\section{Structure-Activity Relationship}

Literature survey revealed that the SAR of thiadiazole for anticonvulsant activity is due to the presence of $=\mathrm{N}-\mathrm{C}-\mathrm{S}-$ moiety and the strong aromaticity of the ring. Other than that, substitution with halo $(\mathrm{Cl}, \mathrm{Br}, \mathrm{F})$, nitro, methyl group aldehyde, hydroxy, and unsubstituted compounds (compounds containing hydrogen) in the ring increases the anticonvulsant activity. An important role is played by lipophilic substitution and electronwithdrawing group on the anticonvulsant activity of the compound.

\section{CONCLUSION}

Thiadiazole moiety is a five-membered ring containing sulfur and nitrogen atoms interconnected with two carbon atoms (electron-deficient), along with a lone pair of electrons, and have high thermotic stability and an electron deficiency. Several pharmacological activities are exhibited by the $1,3,4$ thiadiazole derivative, and it is found to be potent against the anticonvulsant activity of in vivo animal models and MES, PTZ, and neurotoxicity models. The mechanism of action which is responsible for 1,3,4-thiadiazole to act as anticonvulsant agents is by preventing neurons firing in the brain by releasing the chloride ions due to the GABAA pathway. The compound which is substituted with an electron-withdrawing group showed good potency as compared to the electron-withdrawing group. 1,3,4Thiadiazole can be a potent and effective moiety for anticonvulsant research. 


\section{AUTHOR CONTRIBUTIONS}

TA: literature collection and writing of the manuscript. SN: overall supervision

\section{REFERENCES}

Aliyu, A., Idris, A. Y., Musa, A. M., Hamza, A. N., Ahmadu, J. O., Shehu, A., et al. (2021). Design, Synthesis, and In-Vivo Anticonvulsant Evaluation of 5-[(E)-(3, 4, 5trimethoxybenzylidene) Amino]-1, 3, 4-Thiadiazole-2-Thiol. IJSGS 7 (20), 120-127.

Almasirad, A., Vousooghi, N., Tabatabai, S. A., Kebriaeezadeh, A., and Shafiee, A. (2007). Synthesis, Anticonvulsant, and Muscle Relaxant Activities of Substituted 1, 3, 4-oxadiazole, 1, 3, 4-thiadiazole, and 1, 2, 4-triazole. Acta Chim. Slow 54 (2), 317-324.

Belanger, C., P. (1979). 2-(4-substituted-1,2,5-thiadiazole-3-yloxy)-acetaldehydes. U.S. Patent No 4,145,550. Washington, DC: U.S. Patent and Trademark Office.

Bhandari, S. V., Deshmane, B. J., Dangare, S. C., Gore, S. T., Raparti, V. T., Khachane, C. V., et al. (2008). Anticonvulsant Activities of Some Novel 3-[5-substituted, 3, 4Thiadiazole-Yl]-2-Styryl Quinazoline-4 (3h)-Ones. Pharmacologyonline 2, 604-613.

Bhattacharya, S., and Kashaw, V. (2019). Design, Synthesis, and Anticonvulsant Potential of (E)-3-(5-(substituted Aminomethyl)-1, 3, 4-Thiadiazol-2-Yl)-2Substituted Styrylquinazolin-4-(3h)-One. J. Drug Deliv. Ther. 9 (2), 591-602.

Bialer, M., Yagen, B., Sobol, E., and Kaufmann, D. (2007). Amide Derivatives of 2,2,3,3-tetramethylcyclopropane Carboxylic Acid. Washington, DC: U.S. Patent and Trademark Office. U.S. Patent No 7,232,929B2.

Brai, A., Ronzini, S., Riva, V., Botta, L., Zamperini, C., Borgini, M., et al. (2019). Synthesis and Antiviral Activity of Novel 1,3,4-thiadiazole Inhibitors of DDX3X. Molecules 24 (21), 1-18. doi:10.3390/molecules 24213988

Can, Ö. D., Altıntop, M. D., Özkay, Ü. D., Üçel, U. İ., Doğruer, B., and Kaplancıklı, Z. A. (2012). Synthesis of Thiadiazole Derivatives Bearing Hydrazone Moieties and Evaluation of Their Pharmacological Effects on Anxiety, Depression, and Nociception Parameters in Mice. Arch. Pharm. Res. 35 (4), 659-669. doi:10.1007/s12272-012-0410-6

Çevik, U. A., Osmaniye, D., Levent, S., Sağlik, B. N., Çavuşoğlu, B. K., Özkay, Y., et al. (2020). Synthesis and Characterization of a New Series of Thiadiazole Derivatives as Potential Anticancer Agents. Heterocycl. Commun. 26, 6-13. doi:10.1515/hc-2020-0002

Chapleo, C. B., Myers, M., Myers, P. L., Saville, J. F., Smith, A. C. B., Stillings, M. R., et al. (1986). Substituted 1,3,4-thiadiazoles with Anticonvulsant Activity. 1. Hydrazines. J. Med. Chem. 29 (11), 2273-2280. doi:10.1021/jm00161a024

Cristina, A., Leonte, D., Vlase, L., Bencze, L. C., Imre, S., Marc, G., et al. (2018). Heterocycles 48. Synthesis, Characterization and Biological Evaluation of Imidazo[2,1-b][1,3,4]Thiadiazole Derivatives as Anti-inflammatory Agents. Molecules 23, 1-19. doi:10.3390/molecules 23102425

Datar, P., and Deokule, T. (2014). Development of Thiadiazole as an Antidiabetic Agent- a Review. Mrmc 14 (2), 136-153. doi:10.2174/ 1389557513666140103102447

Dawood, K. M., Abdel-Gawad, H., Rageb, E. A., Ellithey, M., and Mohamed, H. A. (2006). Synthesis, Anticonvulsant, and Anti-inflammatory Evaluation of Some New Benzotriazole and Benzofuran-Based Heterocyclesammatory Evaluation of Some New Benzotriazole and Benzofuran-Based Heterocycles. Bioorg. Med. Chem. 14, 3672-3680. doi:10.1016/j.bmc.2006.01.033

Diaz, J. R. A., Camí, G. E., Liu-González, M., Vega, D. R., Vullo, D., Juárez, A., et al. (2016). Salts of 5-Amino-2-Sulfonamide-1,3,4-Thiadiazole, a Structural and Analog of Acetazolamide, Show Interesting Carbonic Anhydrase Inhibitory Properties, Diuretic, and Anticonvulsant Action. J. Enzyme Inhib. Med. Chem. 31 (6), 1102-1110. doi:10.3109/14756366.2015.1096270

Dogan, H. N., Duran, A., Rollas, S., Sener, G., Uysal, M. K., and Gülen, D. (2002). Synthesis of New 2,5-Disubstituted-1,3,4-Thiadiazoles and Preliminary Evaluation of Anticonvulsant and Antimicrobial Activities. Bioorg. Med. Chem. 10, 2893-2898. doi:10.1016/s0968-0896(02)00143-8

Flefel, E. M., El-Sayed, W. A., Mohamed, A. M., El-Sofany, W. I., and Awad, H. M. (2017). Synthesis and Anticancer Activity of New 1-Thia-4-azaspiro[4.5] decane, Their Derived Thiazolopyrimidine and 1,3,4-Thiadiazole Thioglycosides. Molecules 22 (1), 1-13. doi:10.3390/molecules22010170

\section{ACKNOWLEDGMENTS}

The authors would like to thank the Honorable Vice-Chancellor Banasthali Vidyapith Rajasthan for providing the essential facilities.

Foroumadi, A., Sheibani, V., Sakhteman, A., Rameshk, M., Abbasi, M., Farazifard, R. et al. (2007). Synthesis and Anticonvulsant Activity of Novel 2amino-5-[4-Chloro-2(2-Chlorophenoxy)pheny]-1,3,4-Thiadiazole Derivatives. DARU 15 (2), 89-93.

Foroumadi, A., Tabatabai, S. A., Gitinezhad, G., Zarrindast, M. R., and Shafiee, A. (2000). Synthesis and Anticonvulsant Activity of 5-Aryl-1,3,4-Thiadiazole Derivatives. Pharm. Pharmacol. Commun. 6 (1), 31-33. doi:10.1211/ 146080800128735430

Gomha, S. M., Kheder, N. A., Abdelaziz, M. R., Mabkhot, Y. N., and Alhajoj, A. M. (2017). A Facile Synthesis and Anticancer Activity of Some Novel Thiazoles Carrying 1,3,4-thiadiazole Moiety. Chem. Cent. J. 11 (1), 25-29. doi:10.1186/ s13065-017-0255-7

Gowda, K., Swarup, H. A., Nagarakere, S. C., Rangappa, S., Kanchugarkoppal, R. S., and Kempegowda, M. (2020). Structural Studies of 2,5-disubstituted 1,3,4thiadiazole Derivatives from Dithioesters under the Mild Condition: Studies on Antioxidant, Antimicrobial Activities, and Molecular Docking. Synth. Commun. 50 (10), 1528-1544. doi:10.1080/00397911.2020.1745843

Gowramma, B., Kulkarni, A. A., Gomathy, S., and Kandula, R. K. (2012). Synthesis and Anticonvulsant Screening of Some Novel 1, 3, 4 -thiadiazole Derivatives. J. Pharm. Res. 5 (1), 58-60.

Haider, S., Alam, M. S., and Hamid, H. (2015). 1,3,4-Thiadiazoles: A Potent Multi Targeted Pharmacological Scaffold. Eur. J. Med. Chem. 92 (15), 156-177. doi:10.1016/j.ejmech.2014.12.035

Holland, K. (2018). Epilepsy: Facts, Statistics, and You. Healthline. Available at: https://www.healthline.com/health/epilepsy/facts-statistics-infographic.

Husain, A., Naseer, M. A., and Sarafroz, M. (2009). Synthesis and Anticonvulsant Activity of Some Novel Fused Heterocyclic 1,2,4-Triazolo-[3,4-B]-1,3,4Thiadiazole Derivatives. Acta Pol. Pharm. 66 (2), 135-140.

Jain, A. K., Sharma, S., Vaidya, A., Ravichandran, V., and Agrawal, R. K. (2013). 1,3,4-Thiadiazole and its Derivatives: A Review on Recent Progress in Biological Activities. Chem. Biol. Drug Des. 81 (5), 557-576. doi:10.1111/cbdd.12125

Janowska, S., Paneth, A., and Wujec, M. (2020). Cytotoxic Properties of 1,3,4Thiadiazole Derivatives-A Review. Molecules 25 (18), 1-41. doi:10.3390/ molecules25184309

Jatav, V., Mishra, P., Kashaw, S., and Stables, J. P. (2008). CNS Depressant and Anticonvulsant Activities of Some Novel 3-[5-substituted 1,3,4-Thiadiazole-2Yl]-2-Styryl Quinazoline-4(3h)-Ones. Eur. J. Med. Chem. 43, 1945-1954. doi:10.1016/j.ejmech.2007.12.003

Joseph, L., George, M., and Mathews, P. (2015). A Review on Various Biological Activities of 1,3,4-thiadiazole Derivatives. J. Pharm. Chem. Biol. Sci. 3 (3), 329-345.

Karakus, S., Koçyığt-Kaymakcioglu, B., Toklu, H. Z., Aricioglu, F., and Rollas, S. (2009). Synthesis and Anticonvulsant Activity of NewN-(Alkyl/Sub-Stituted Aryl)-N'-[4-(5-Cyclohexylamino)-1,3,4-Thiadiazole-2-Yl)phenyl]thioureas. Arch. Pharm. Chem. Life Sci. 342, 48-53. doi:10.1002/ardp.200800118

Karimian, K., Tam, F., T., Desilets, D., Lee, S., Cappelletto, T., and Li, W. (1997). Thiazole Compounds Are Useful as Proton Pump Inhibitors. U.S. Patent No 5,677,302. Washington, DC: U.S. Patent and Trademark Office,

Kaur, H., Kumar, S., Vishwakarma, P., Sharma, M., Saxena, K. K., and Kumar, A. (2010). Synthesis and Antipsychotic and Anticonvulsant Activity of Some New Substituted Oxa/thiadiazolylazetidinonyl/thiazolidinonylcarbazoles. Eur. J. Med. Chem. 45, 2777-2783. doi:10.1016/j.ejmech.2010.02.060

Khatoon, Y., Singh, V., and Sarafroz, M. (2018). Anticonvulsant and Neurotoxicity Evaluation of Some Fused 1,2,4-Triazole-[3,4-B]-1,3,4-Thiadiazole Derivatives. Int. J. Pharm. Sci. Rev. Res. 48 (2), 70-78.

Khazi, I. A., Mahajanshetti, C. S., Gadad, A. K., Tarnalli, A. D., and Sultanpur, C. M. (1996). Synthesis, Anticonvulsant and Analgesic Activities of Some 6substituted Imidazo(2,1-B)-1,3,4-Thiadiazole-2-Sulfonamides and Their 5bromo Derivatives. Arzneimittelforschung 46 (10), 949-952.

Kikkeri, H. P., Kikkeri, M. N., and Lingappa, M. (2013). Synthesis of Pyrazine Substituted 1, 3, 4-thiadiazole Derivatives and Their Anticonvulsant Activity. Org. Chem. Int., 1-8. 
Klein, E. (2019). Symptoms, Causes, and Treatment of Epilepsy. Brighton: Medical News Today. Available at; https://www.medicalnewstoday.com/articles/8947.

Kumudha, D., Reddy, R. R., and Kalavathi, T. (2014). Synthesis and Evaluation of Some 1, 3, 4-thiadiazoles Having Substituted 1, 2, 4-triazole Moiety for Anticonvulsant and CNS Depressant Activity. World J. Pharm. Pharm. Sci. 3 (9), 728-740.

Löscher, W. (2011). Critical Review of Current Animal Models of Seizures and Epilepsy Used in the Discovery and Development of New Antiepileptic Drugs. Seizure 20 (5), 359-368. doi:10.1016/j.seizure.2011.01.003

Luszczki, J. J., Karpińska, M., Matysiak, J., and Niewiadomy, A. (2014). Characterization and Preliminary Anticonvulsant Assessment of Some 1,3,4thiadiazole Derivatives. Pharmacol. Rep. 67 (3), 588-592. doi:10.1016/ j.pharep.2014.12.008

Madhu Sekhar, M., Nagarjuna, U., Padmavathi, V., Padmaja, A., Reddy, N. V., and Vijaya, T. (2018). Synthesis and Antimicrobial Activity of Pyrimidinyl 1,3,4oxadiazoles, 1,3,4-thiadiazoles and 1,2,4-triazoles. Eur. J. Med. Chem. 145, 1-10. doi:10.1016/j.ejmech.2017.12.067

Malygin, A. S., Demidova, M. A., Skachilova, S. Y., and Shilova, E. V. (2020). Synthesis of a Novel Amide Derivative of Valproic Acid and 1,3,4-thiadiazole with Antiepileptic Activity. Brsmu 1, 75-80. doi:10.24075/brsmu.2020.007

Manimaran, T., Anand, R. M., Jishala, M. I., and Gopalasatheeskumar, K. (2017). Review on Substituted 1,3,4-thiadiazole Compounds. IJPAR 6 (2), 222-231.

Masi, H. H., Gajjor, A. K., Savjani, J. K., and Masi, I. (2011). Synthesis and Anticonvulsant Activity of Novel 2,5-disubstituted 1, 3, 4-thiadiazole Derivatives. Int. J. Pharmtech. Res. 3 (4), 2017-2024.

Merugu, S., Ponnamaneni, V. K., Varala, R., Adil, S. F., Khan, M., Siddiqui, M. R. H., et al. (2020). Metal-free Catalyzed One-Pot Multicomponent Synthesis of (E)-3-(2-((5-(Benzylideneamino)-1,3,4-thiadiazol-2-yl)thio) Acetyl)-2hChromen-2-One Derivatives and Their Biological Evaluation. J. Chem. 2020, 1-7. doi:10.1155/2020/4869279

Mutchu, B. R., Kotra, V., Onteddu, S. R., Boddapati, S. M. N., and Bollikolla, H. B. (2019). Synthesis, Cytotoxicity, and Antimicrobial Evaluation of Some New 2aryl, 5-substituted 1, 3, 4-oxadiazoles and 1, 3, 4-thiadiazoles. Chem. Africa 2, 1-6. doi:10.1007/s42250-018-00034-x

Ningegowda, R., Shivananju, N. S., Rajendran, P., BasappaRangappa, K. S., Chinnathambi, A., et al. (2017). A Novel 4,6-Disubstituted-1,2,4-Triazolo1,3,4-Thiadiazole Derivative Inhibits Tumor Cell Invasion and Potentiates the Apoptotic Effect of TNFa by Abrogating NF-Kb Activation cascade. Apoptosis 22 (1), 145-157. doi:10.1007/s10495-016-1312-8

Pandeya, S. N., Raja, A. S., and Stables, J. P. (2002). Synthesis of Isatin Semicarbazones as Novel Anticonvulsants-Rrole of Hydrogen Bonding. J. Pharm. Pharm. Sci. 5 (3), 266-271.

Pattanayak, P., Sharma, R., and Sahoo, P. K. (2009). Synthesis and Evaluation of 2Amino-5-Sulfanyl-1,3,4-Thiadiazoles as Antidepressant, Anxiolytic, and Anticonvulsant Agents. Med. Chem. Res. 18, 351-361. doi:10.1007/s00044-0089132-1

Poveda, G., Manuel, P., Aguilar, I., NuriaMircepeda, M., Martinez, L., and Manuel (2010). New 2-aminothiadiazol Derivatives. Geneva, Switzerland: International Publication NoWorld Intellectual Property Organization International Bureau. WO 2010/043377 A1.

Quesnel, Y., Turet, L., and Mercier, J. (2015). 2-oxo-1-pyrrolidinyl Imidazothiadiazole Derivatives. European Patent No 2491. Munich, Germany: European Patent Office 045B1.

Rahman, M. A., Shakya, A. K., Wahab, S., and Ansari, H. N. (2014). Synthesis of Some New Thiadiazole Derivatives and Their Anticonvulsant Activity. Bulg. Chem. Commun. 46 (4), 750-756.

Raj, V., Rai, A., Singh, M., Kumar, R., Kumar, A., Kumar, V., et al. (2015). Recent Update on 1, 3, 4-thiadiazole Derivatives: as Anticonvulsant Agents. Am. Res. J. Pharm. 1 (1), 34-61.

Rajak, H., Behera, C. K., Pawar, R. S., Singour, P. K., and Kharya, M. D. (2010). Synthesis and Anticonvulsant Evaluation of Some Novel 2,5-disubstituted 1,3,4-thiadiazoles: Pharmacophore Model Studies. Acta Pol. Pharm. 67 (5), 503-510.

Rajak, H., Thakur, B. S., Kumar, P., Parmar, P., Sharma, P. C., Veerasamy, R., et al. (2012). Synthesis and Antiepileptic Activity of Some Novel Semicarbazones Containing 1,3,4-thiadiazole and Quinazoline Ring. Acta Pol. Pharm. 69 (2), 253-261.
Sadat-Ebrahimi, S. E., Mirmohammadi, M., Mojallal Tabatabaei, Z., Azimzadeh Arani, M., Jafari-Ashtiani, S., Hashemian, M., et al. (2019). Novel 5(nitrothiophene-2-Yl)-1,3,4-Thiadiazole Derivatives: Synthesis and Antileishmanial Activity against Promastigote Stage of Leishmania Major. Iran J. Pharm. Res. 18 (4), 1816-1822. doi:10.22037/ijpr.2019.14547.12476

Sahoo, B. M., Dinda, S. C., Ravi Kumar, B. V., Panda, J. R., and Brahmkshatriya, P. S. (2013). Molecular Docking Study, green Synthesis and Pharmacological Evaluation of 1,3,4-thiadiazole Derivatives as Potential Antiepileptic Agents. Mini Rev. Med. Chem. 13 (14), 2076-2081. doi:10.2174/13895575113136660099

Sahoo, B. M., Dinda, S. C., and Kumar, B. V. V. R. (2012). Design, Synthesis, and Antiepileptic Evaluation of 5-(aryl)-N-Phenyl-1,3,4-Thiadiazol-2-Amine. Int. J. Pharm. Sci. 4 (3), 747-751.

Samel, A. B., and Pai, N. R. (2010). Synthesis of Novel Aryloxy Propanoyl Thiadiazoles as Potential Antihypertensive Agents. Jnl Chin. Chem. Soc 57, 1327-1330. doi:10.1002/jccs.201000196

Sarafroz, M., Khatoon, Y., Ahmad, N., Amir, M., Salahuddin, S., and Hyder Pottoo, F. (2019). Synthesis, Characterization and Anticonvulsant Activity of Novel Fused 1,2,4-Triazolo-1,3,4-Thiadiazoles. Orient. J. Chem. 35 (1), 64-70. doi:10.13005/ojc/350107

Schenone, S., Brullo, C., Bruno, O., Bondavalli, F., Ranise, A., Filippelli, W., et al. (2006). New 1,3,4-thiadiazole Derivatives Endowed with Analgesic and Antiinflammatory Activities. Bioorg. Med. Chem. 14 (6), 1698-1705. doi:10.1016/ j.bmc.2005.10.064

Serban, G. (2020). Synthetic Compounds with 2-Amino-1,3,4-Thiadiazole Moiety against Viral Infections. Molecules 25 (4), 1-22. doi:10.3390/molecules25040942

Serban, G., Stanasel, O., Serban, E., and Bota, S. (2018). 2-Amino-1,3,4-thiadiazole as a Potential Scaffold for Promising Antimicrobial Agents. Dddt 12, 1545-1566. doi:10.2147/dddt.s155958

Sharma, B., Verma, A., Sharma, U. K., and Prajapati, S. (2014). Efficient Synthesis, Anticonvulsant and Muscle Relaxant Activities of New 2-((5-Amino-1,3,4Thiadiazol-2-Yl)methyl)-6-Phenyl-4,5-Dihydropyridazin-3(2h)-One Derivatives. Med. Chem. Res. 23, 146-157. doi:10.1007/s00044-013-0618-0

Sharma, R., Misra, G. P., Sainy, J., and Chaturvedi, S. C. (2011). Synthesis and Biological Evaluation of 2-Amino-5-Sulfanyl-1,3,4-Thiadiazole Derivatives as Antidepressant, Anxiolytics and Anticonvulsant Agents. Med. Chem. Res. 20, 245-253. doi:10.1007/s00044-010-9308-3

Siddiqui, N., Rana, A., Khan, S. A., Haque, S. E., Arshad, M. F., Ahmed, S., et al. (2009). Synthesis and Preliminary Screening of Benzothiazol-2-Yl Thiadiazole Derivatives for Anticonvulsant Activity. Acta Pharm. 59, 441-451. doi:10.2478/ v10007-009-0031-x

Siddiqui, N., Ahuja, P., Malik, S., and Arya, S. K. (2013). Design of Benzothiazole1,3,4-Thiadiazole Conjugates: Synthesis and Anticonvulsant Evaluation. Arch. Pharm. Chem. Life Sci. 346, 819-831. doi:10.1002/ardp.201300083

Skrzypeka, A., Matysiaka, J., Karpinskab, M., Czarneckac, K., Kreciszc, P., Staryd, D., et al. (2021). Biological Evaluation and Molecular Docking of Novel 1,3,4-Thiadiazole-Resorcinol Conjugates as Multifunctional Cholinesterases Inhibitors. Bioorg. Chem. 107, 1-11. doi:10.1016/ j.bioorg.2020.104617

Stamos, D., Martinborough, E., Neubert, T., Numa, M., Whitney, T., et al. (2009). Heterocyclic Derivatives as Modulators of Ion Channels. Geneva, Switzerland: World Intellectual Property Organization International Bureau. International Publication No WO 2009/064752 A2.

Stillings, M. R., Welbourn, A. P., and Walter, D. S. (1986). Substituted 1,3,4thiadiazoles with Anticonvulsant Activity. 2. Aminoalkyl Derivatives. J. Med. Chem. 29 (11), 2280-2284. doi:10.1021/jm00161a025

Tahghighi, A., and Babalouei, F. (2017). Thiadiazoles: the Appropriate Pharmacological Scaffolds with Leishmanicidal and Antimalarial Activities: a Review. Iran. J. Basic Med. Sci. 20 (6), 613-622. doi:10.22038/IJBMS.2017.8828

Thrilochana, P., Sahu, C. N., Hazra, K., and Ramachandran, S. (2014). Synthesis and Biological Evaluation of New Thiadiazole Analogs for Anti-diabetic Activity against Alloxan-Induced Diabetes. J. Pharm. Res. 8 (11), 1-8.

Toolabi, M., Khoramjouy, M., Aghcheli, A., Ayati, A., Moghimi, S., Firoozpour, L., et al. (2020). Synthesis and Radioligand-Binding Assay of 2,5-disubstituted Thiadiazoles and Evaluation of Their Anticonvulsant Activities. Arch. Pharm. (Weinheim) 353 (12), e2000066-9. doi:10.1002/ ardp. 202000066 
Tripathi, K. D. (2013). Essentials of Medical Pharmacology. New Delhi: Replika Press.

Vaishnav, Y., Jha, A. K., Verma, S., Kashyap, P., and Kaur, C. D. (2017). A Review on Antidiabetic Activity of Substituted 1,3,4-thiadiazole Derivatives. Res. J. Pharm. Tech 10 (2), 4467-4470. doi:10.5958/0974360x.2017.00824.1

Varvaresou, A., Siatra-Papastaikoudi, T., Tsotinis, A., Tsantili-Kakoulidou, A., and Vamvakides, A. (1998). Synthesis, Lipophilicity and Biological Evaluation of Indole-Containing Derivatives of 1,3,4-thiadiazole and 1,2,4-triazole. IL Farmaco 53, 320-326. doi:10.1016/s0014-827x(98)00024-x

Yakan, H. (2021). Synthesis, Characterization, and Antioxidant Activities of New 1,3,4-thiadiazoles Based on Benzoic Acid. ECJSE 8 (1), 155-163. doi:10.31202/ ecjse. 794370

Yar, M. S., and Akhter, M. W. (2009). Synthesis and Anticonvulsant Activity of Substituted Oxadiazole and Thiadiazole Derivatives. Acta Pol. Pharm. 66 (4), 393-397.
Conflict of Interest: The authors declare that the research was conducted in the absence of any commercial or financial relationships that could be construed as a potential conflict of interest.

Publisher's Note: All claims expressed in this article are solely those of the authors and do not necessarily represent those of their affiliated organizations, or those of the publisher, the editors, and the reviewers. Any product that may be evaluated in this article, or claim that may be made by its manufacturer, is not guaranteed or endorsed by the publisher.

Copyright (C) 2022 Anthwal and Nain. This is an open-access article distributed under the terms of the Creative Commons Attribution License (CC BY). The use, distribution or reproduction in other forums is permitted, provided the original author(s) and the copyright owner(s) are credited and that the original publication in this journal is cited, in accordance with accepted academic practice. No use, distribution or reproduction is permitted which does not comply with these terms. 